\title{
1 Predicting the time of green up in temperate and boreal Biomes
}

2

3 Jörg D. Kaduk (1), Sietse O. Los (2)

4

5 (1) Department of Geography

$6 \quad$ University of Leicester

7 University Road

8 Leicester, LE1 7RH

$9 \quad$ United Kingdom

10

11 (2) Department of Geography

12 Swansea University

13 Singleton Park

14 Swansea, SA2 8PP

15 United Kingdom

16

17

18

19 Keywords: Phenology, Phenological models, budburst, climate change, boreal and temperate 20 biomes, vegetation modelling

21

22

23 Corresponding author:

24 Jörg D. Kaduk

25 j.kaduk@leicester.ac.uk / Phone: +44 (0) 1162523848 / FAX: +44 (0) 1162523852 


\section{Predicting the time of green up in temperate and boreal Biomes}

\section{2 determined from NDVI}

\section{Abstract}

5 Normalized Difference Vegetation Index (NDV) data from satellites and ground observations have shown earlier leaf appearance in the northern hemisphere, which is believed to result from climate warming. The advance of leaf out to earlier times in the year could be limited or even reversed,

8 however, as temperate and boreal trees require a certain amount of chilling in winter for rapid leaf

9 out in spring. If this chilling requirement is not fulfilled, an increasing amount of warming is

10 required for leaf out. Implications of these chilling requirements at the biome level are not clear.

11 One approach to estimate their importance is to generalize the exponential relationships between chilling and warming established for single species. Previous work using NDVI data suggests that

13 this is indeed feasible but much has been limited to specific biomes or a very few years of data for 14 the modelling.

15 We find chilling requirements for northern temperate and boreal biomes by fitting various phenology models to green-up dates determined from NDVI using various methods and 12 years of data. The models predict that in northern middle and high latitudes the advance of green-up will be limited to a total of four to five days on average (but up to 15 days regionally) over the time period 2000-2060 as estimated using two contrasting climate simulations. This results from the exponentially increasing warming requirements for leaf out when winter chilling falls below a

21 threshold as shown by a comparison with models that consider only spring warming. The model evaluation suggests an element of regional adaptation of the warming required for leaf out in large

23 biomes. 


\section{1. Introduction}

2 Leaf phenology is linked with the carbon, water and energy exchange between the land surface and

3 the atmosphere on hourly to interannual time scales. One of the most important aspects of leaf

4 phenology is leaf emergence as it modifies the atmospheric boundary layer and thus introduces

5 feedbacks with the local and regional climate (Fitzjarrald et al., 2001; Freedman et al., 2001; Taylor

6 et al., 1997). Incorporation of leaf phenology from remote sensing (RS) data in general circulation

7 models (GCMs) has lead to an improved representation of carbon fluxes and of latent heat and

8 sensible heat fluxes (Lawrence and Slingo, 2004; Randall et al., 1996; Van den Hurk et al., 2003).

9 Land-surface parameterizations in GCMs, however, do not entail robust models for the prediction

10 of leaf phenology.

12 The atmospheric $\mathrm{CO}_{2}$ record (Keeling et al., 1996), observations in phenological gardens (Menzel,

13 2000) and NOAA Advanced Very High Resolution Radiometers (AVHRR) Normalized Difference

14 Vegetation Index (NDVI) show an earlier start and later end of the growing season in the northern

15 hemisphere as well as a larger annual amplitude in the 1990s compared to earlier decades (Myneni

16 et al., 1997; Shabanov et al., 2002). While the earlier increase of the NDVI could at least partly

17 reflect earlier snow melt, the earlier start of the growing season found in ground observations of

18 phenology and the changes in the seasonal cycle of the atmospheric $\mathrm{CO}_{2}$ concentration $\left(\left[\mathrm{CO}_{2}\right]_{\mathrm{a}}\right)$

19 imply a large scale earlier green up of vegetation (Keeling et al., 1996; Menzel and Fabian, 1999;

20 Randerson et al., 1999; Sparks et al., 1997).

21 Thus the observed NDVI increase in spring can be interpreted as a plant physiological response to

22 increasing temperatures in the northern latitudes in a consistent and compelling way, although some

23 part of the NDVI increase is likely caused by earlier snow melt and the resulting feedbacks to

24 regional climate (Dye and Tucker, 2003; Shabanov et al., 2002). 
1 The relationship between leaf budburst and temperature is, however, more intricate than a direct

2 response of growth to spring warming. Controlled experiments show that many temperate and

3 boreal tree species require a period of cool temperatures (below $10^{\circ} \mathrm{C}$ ) in winter for rapid budburst

4 in response to warming in spring (Chuine and Cour, 1999; Murray et al., 1989; Myneni et al.,

5 1997). If the amount of chilling falls below a certain threshold more warming is required to initiate

6 budburst. In these experiments the amount of chilling is measured in the number of days with an

7 average temperature below some threshold ("Number of Chill Days", NCD) counted from a start

8 date. The warm period is measured as a heat sum, typically the number of hours or days with an

9 average temperature above another threshold since another start date and is referred to as "Growing

10 Degree Days" (GDD) or "thermal time". The experiments show that when for a single a certain

11 threshold NCD, the "chilling requirement", is exceeded, plants will leaf out with minimal GDD.

12 When, however, the chilling requirement cannot be fulfilled (e.g. due to warm winters) then the

13 GDD requirement for leaf out increases in an exponential fashion with decreasing chilling received

14 (Cannell and Smith, 1986; Chuine and Cour, 1999; Murray et al., 1989; Myneni et al., 1997).

15 The observed earlier green-up in the northern hemisphere reflects warmer springs (any given GDD

16 is reached earlier) and a still satisfied chilling requirement; or at least the lost NCD are compensated

17 for by a sufficiently large increase in GDD.

18 A significant drop in the NCD, however, could lead to delayed budburst due to the exponentially

19 increasing GDD requirements with decreasing NCD (Cannell and Smith, 1986; Murray et al.,

20 1989), or at least a significant slowing of the advancement of leaf appearance to earlier times.

21 Thus, paradoxically, there is a distinct possibility that global warming and associated warmer

22 springs, which are predicted to be most pronounced in the high northern latitudes, will lead to a

23 delayed budburst and this could provide a negative feedback to earlier greening of vegetation in

24 spring. This effect is at present not incorporated in land-surface models and this leads to 
1 uncertainties in projections of climate change, associated greening of land-surface vegetation and

2 the magnitude of the land-surface carbon sink.

4 To improve the representation of the timing of green-up in land surface models (coupled to GCMs),

5 we translate the exponential relationships between chilling and heat accumulation established for

6 single species to relationships for whole biomes. Previous work (Botta et al., 2000; Kaduk and

7 Heimann, 1996) suggests that similar relationships hold for both.

8 For some biomes, however, the analysis of RS data indicates that simpler models using only

9 chilling or warming give equally good or even better results (Botta et al., 2000; Picard et al., 2005).

10 We show in this paper, that this might be a consequence of a sampling design that is either too

11 limited in space, only fairly small regions are used, or in time, only one year of data is used. In our

12 current analysis we exploit the information available in data sets that cover a time span of 12 years

13 and cross validate our models on data not used for their calibration.

15 We use various methods to determine the time of green-up from the FASIR NDVI data 1984-1995

16 (Los et al., 2000), e.g. (Kaduk and Heimann, 1996; Moulin et al., 1997; White et al., 1997) and then

17 explore commonly used phenology model as well as derive new models that predict the time of the

18 green-up in temperate and boreal biomes from GDD and NCD. Moreover, since it is widely

19 assumed that tree phenology adapts to the local climate, i.e. that provenance plays a role in leaf

20 dynamics, we explore in particular the question of whether phenology models can be improved by

21 taking local temperature averages into account. We show that it is crucial to use multiple years of

22 data to obtain stable models and reliable estimates for the prediction error. Finally we apply our

23 models to estimate the sensitivity of green-up to chilling requirement for two projected warming

24 scenarios in the middle of the 21 st century. 
1 Our aims are to: a) estimate the effect of chilling requirements on earlier green up at the biome

2 level; b) derive climate driven phenology models that determine green-up for northern temperate

3 and boreal biomes as these are predicted to be most affected by global warming, which are

4 appropriate for landscape scale land surface models, c) evaluate whether there are local adaptations

5 of green-up apparent within the biomes and d) explore the possible future change in green-up.

6 As we consider large spatial scales we do not refer to "leaf budburst", which suggests local scale or

7 individual plants, and instead use the term "green-up" by which we mean the time of the beginning

8 of landscape scale leaf display.

9 2. Data and Methods

\subsection{Input data sets}

\subsubsection{Land cover}

12 We use the University of Maryland (UMd) $0.5 \times 0.5^{\circ}$ global land cover from the International

13 Satellite Land Surface Climatology Project (ISLSCP) initiative II (Hall et al., 2005; Hansen et al., 14 2000) as vegetation distribution. It distinguishes 14 classes and details the percentage cover of each 15 class for each $0.5 \times 0.5^{\circ}$ pixel. We consider the following classes (1) Evergreen Needleleaf Forest 16 (ENF), (3) Deciduous Needleleaf Forest (DNF), (4) Deciduous Broadleaf Forest (DBF), (5) Mixed 17 Forests (MixF), (6) Woodlands (Wdld), and (9) Open Shrublands (OpSh) (Table 1). The UMd land18 cover data set also details the percentage cover of each class for each $0.5 \times 0.5^{\circ}$ pixel. The 19 classification does not distinguish between tropical and temperate broadleaf forests; thus DBF 20 comprises temperate deciduous and tropical dry deciduous broadleaf forest. The phenological

21 processes of temperate (and boreal) and tropical vegetation are, however, determined by different 22 climate variables; we limit ourselves here to the temperate and boreal areas and we identify these 23 areas based on latitude (section 2.3). 
2 We use the 10 -day, $0.5 \times 0.5^{\circ}$ NDVI data from ISLSCP II (FASIR NDVI version 4.131 ) for the

3 years 1984-1995, that are derived from the Pathfinder AVHRR Land project (PAL) data. PAL data

4 are corrected for sensor degradation, atmospheric ozone absorption, Rayleigh scattering and sensor

5 differences of successive NOAA platforms (James and Kalluri, 1994). The FASIR (Fourier

6 adjusted, sensor and solar zenith angle corrected, interpolated and reconstructed) NDVI is

7 additionally corrected for: (1) residual sensor degradation and differences in sensor calibration (Los,

8 1998), (2) volcanic aerosol effects resulting from the eruption of El Chichon (1982) and Mt

9 Pinatubo (1991) (Los et al., 2000), (3) BRDF effects (Los et al., 2005), (4) dense cloud cover over

10 tropical forests (Behrenfeld et al., 2001), (5) short-term atmospheric and cloud effects (Los et al.,

11 2000; Sellers et al., 1996), and (6) missing winter data over the boreal forest (Los et al., 2000;

12 Sellers et al., 1996).

13 Using 10-day instead of monthly NDVI partially remedies the fact that the NDVI tends to be biased

14 towards later dates in the early growing season due to the maximum value compositing during

15 processing of the NDVI (Holben, 1986; James and Kalluri, 1994).

16 To evaluate the effect of the interpolation and adjustment of the FASIR data on derived green-up

17 dates we also use the data set without the Fourier Adjustment and Interpolation corrections and

18 refer to these data as viASR.

19 We selected the FASIR NDVI data in order to have a long consistent time series of RS data

20 concurrent with a consistent, observation based consistent global temperature data set (the GSWP-2

21 data of Zhao and Dirmeyer (2003) (see 2.1.4). A larger number of years allows for a better

22 calibration and evaluation of the green-up models than would be possible with fewer years. We

23 resolve the problem of erroneously identifying snow-melt as green-up by considering snow cover

24 data (Armstrong and Brodzik, 2002). 
1 The NDVI is sensitive to the presence of snow; snowmelt and green-up have similar radiative

2 signatures in the AVHRR NDVI, as do snowfall and leaf-fall (Shabanov et al., 2002). We therefore

3 use the weekly $25 \mathrm{~km}$ snow cover data from the National Snow and Ice Data Center (NSIDC)

4 (Armstrong and Brodzik, 2002) to determine periods of snow cover for each pixel. We consider a

5 pixel to be snow covered if the central point is snow covered according to these data in the week

6 that has the largest temporal overlap with the 10-day period of the NDVI data under consideration.

\subsubsection{Temperature}

8 For the determination of GDDs and NCDs for the phenology models we use daily averages of the

9 global 3 hourly, $1 \times 1^{\circ}$ near surface temperature reanalysis data from the NCEP-DOE Reanalysis 2

10 which were hybridized with the University of East Anglia CRU data set 1983-1996 from the

11 GSWP-2 (Zhao and Dirmeyer, 2003).

12 To evaluate the potential future changes in the time of green-up we use climate predictions for

13 2051-2060 from the MPI ECHAM5 GCM for the IPCC Forth Assessment Report (FAR)

14 (obtainable from PCMDI: http://www-pcmdi.llnl.gov/ipcc/about_ipcc.php). We use two contrasting

15 climate change scenarios, SRES A2 and B1, to span a range of temperature predictions: the A2

16 storyline describes a very heterogeneous world with high population growth and a significant

17 increase in global temperatures; and the B1 storyline describes a convergent world with low

18 population growth and a more moderate increase in global temperatures (IPCC, 2000). We use the

19 data for $1981-2000$ from the $20^{\text {th }}$ century climate simulation for comparison and data adjustment as

20 follows: we reduce the biases due to an incorrect mean state of the GCM by calculating daily

21 anomalies for all simulations and adding them to the 1983-1995 mean of the GSWP-2 daily means.

22 The anomalies are calculated for each day of the 10 years of the projections 2051-2060 and for

23 1986-1995 with respect to the 2046-2065 and the 1981-2000 means respectively. For comparing

24 with the $20^{\text {th }}$ century climate simulation we add the simulated 1986-1995 daily anomalies to the

25 1983-1995 means of the GSWP-2 temperatures. For comparing with climate change projections we Page 8 
1 add the difference between the simulated 2046-2065 and the 1981-2000 daily means to the daily

2 means of the GSWP-2 temperatures, to account for the mean change in climate, and then add the

3 daily 2051-2060 anomalies.

\subsection{Determination of green-up from NDVI}

5 Our derivation of green-up models (Figure 1) starts with the determination of green-up from NDVI

6 separately for each $0.5^{\circ}$ pixel. Several methods to determine a "leaf-out date" from remotely sensed

7 data exist. For example, White et al., (1997) calculate green up from the midpoint between the

8 annual minimum and maximum NDVI. Moulin et al., (1997) determine green-up as the largest

9 increase in NDVI above a threshold. Kaduk and Heimann, (1996) use the largest increase in the

10 NDVI after the mean monthly temperature reached $5^{\circ} \mathrm{C}$ as an indication of green-up. More recently,

11 Kang et al. (2003) explored a threshold approach similar to the one of White et al. (1997) using

12 MODIS leaf area index (LAI) data. Zhang et al. (2003) propose the time of the largest curvature of

13 exponential functions fitted to the EVI as the time of green-up.

14 For detecting green-up in northern latitudes it is crucial to distinguish between the NDVI increases

15 related to snow melt and to greening of vegetation. This problem is dealt with in different ways:

16 White et al., (1997) use a large NDVI threshold, Kaduk and Heimann (1996) use a temperature

17 threshold above which snow occurrence is unlikely, Zhang et al. (2003) use quality assurance (QA)

18 flags to select snow free NDVI data. Delbart et al. (2005) used the Normalized Difference Water

19 Index (NDWI), which is sensitive to water on the land surface and therefore potentially allows for

20 determination of the time period between snow-melt and budburst. However, the NDWI is only

21 available for a limited number of years and does not overlap with the GSWP-II data. Moreover, the

22 NDWI can not detect vegetation greenness changes if the soil surface is already very wet (saturated

23 or standing water), which is common after snow melt, and there are issues with the calibration that 
1 impact the trend in the data (Hüttich et al., 2006). We therefore prefer to use snow cover data to

2 explicitly indicate the end of snow melt and potential begin of large scale green-up.

4 We use the following methods to infer green-up from the NDVI data:

5 a) the relative threshold based method of White et al. (1997),

6 b) a curvature method similar to the approach of Zhang et al. (2003), though, instead of determining

7 the maximum curvature of fitted exponentials, we simply fit cubic splines (natural) to the NDVI

8 (using the spline function from (Press et al., 2002)) and record the date of the largest second

9 derivative of the spline before the maximal NDVI in a year as the time of green-up,

10 c) a method incorporating a climate condition (Kaduk and Heimann, 1996), which we modify by

11 taking the largest increase in NDVI after the 30 day running mean temperature reached $5^{\circ} \mathrm{C}$, instead

12 of the mean monthly temperature, and

13 d) the curvature method of Moulin et al. (1997) for which we exclude "evergreen" and "desert"

14 pixels. Note, however, that we are using a different NDVI and vegetation classification than Moulin

15 et al. (1997). We record the time of the first minimum of the index as defined by Moulin et al.

16 (1997) before the maximal NDVI of the year as the time of green-up.

17 All these four methods detect green-up for a pixel based on the information relating to that pixel.

18 They are therefore insensitive to changes of the optical properties of the surface across the fairly

19 large land cover classes.

20 For all methods we set green-up to occur on day five of the 10 day period for which it is indicated

21 by the NDVI data. We record whether the pixel is still snow covered according to the snow cover 22 data and determine the first snow free detection.

\subsection{Definition of biome areas}


1 The UMd land cover classes reflect only plant growth form and do not represent meaningful biomes

2 in the sense of an assemblage of climate adapted plant functional types. Our aim here is to define

3 large scale bioclimatic regions by being as inclusive as possible but still arrive at meaningful

4 delineations of temperate and boreal biomes. We therefore divide the UMd land cover classes

5 mainly on the basis of latitude. This implicitly uses climate, since temperature and latitude are

6 correlated, however, it stills result in more varied biomes. We accept more variation in the

7 occurrence of plant functional types in our biomes and thus potentially larger errors in the derived

8 green-up models to gain wider applicability of the models. To support the selection of the latitudes

9 delineating the biomes we also examined the growing degree days (GDD, $S_{f}(t)$, for the definitions of

10 symbols see Table 2), and the number of chilling days (NCD, $\left.S_{c}(t)\right)$ at green-up. We used the

11 following set of rules:

12 - For Evergreen Needleleaf Forest (ENF) pixels located south of $45^{\circ} \mathrm{N}$ predominantly in the

13 southern US and southern Japan (Figure 2, Figure 4) show high GDD at green-up. We do not

14 consider these areas to be temperate or boreal coniferous forest and limit our analysis to areas north

15 of $45^{\circ} \mathrm{N}$.

16 - In Deciduous Needleleaf Forest (DNF) six pixels showed high GDD and NCD according to

17 method c) compared to all other pixels. All of them were located west of $100^{\circ} \mathrm{E}$, in the more western

18 population of deciduous needleleaf forest dominated by Larch (Figure 2). We exclude the eight

19 pixels of this biome west of $100^{\circ} \mathrm{E}$ from our analysis. While this might bias our analysis towards the

20 more eastern Larch stands, we believe that potential misclassification (these 8 pixels have just about

$2150 \%$ cover by class 3 ) justifies the exclusion.

22 - For Deciduous Broadleaf Forest (DBF) the areas south of $30^{\circ} \mathrm{N}$ which showed rather high GDD

23 and low NCD are excluded. These pixels are located on Yukatan and in South-East Asia, which we

24 do not consider temperate deciduous forest. For this biome we limit our analysis therefore to areas

25 North of $30^{\circ} \mathrm{N}$. 
1 - In Mixed Forest (MixF) and Woodland (Wdld) we consider here only the areas north of $45^{\circ} \mathrm{N}$. The

$2 \mathrm{NCD}$ and GDD requirements seem to be quite different north and south of $45^{\circ} \mathrm{N}$ (Figure 3). This

3 reasonable as in Mediterranean climate a limited number of cold days can serve as an indicator that

4 the winter is over, whereas in the more temperate and boreal areas a higher chilling requirement is

5 appropriate.

6 - From Open Shrublands (OpSh), which comprises tundra and deserts in the interior of the

7 continents south of $45^{\circ} \mathrm{N}$, which tend to have rain driven phenology, we want to consider mainly the

8 tundra. We limit our analysis therefore to the area north of $50^{\circ} \mathrm{N}$ (we use 50 instead of $45^{\circ} \mathrm{N}$ solely

9 to exclude the Gobi completely). We also excluded one pixel at $70^{\circ} \mathrm{N}$, which had a GDD of more

10 than 1200 in method c).

12 We also exclude all pixels that have a GDD larger than 1000 in order to remove the extreme tail of

13 the GDD distribution. This condition resulted in dropping only around 5\% and $2 \%$ of the data in

14 biomes ENF and DBF respectively, and of less than $1 \%$ in the other biomes.

16 These restrictions allow us to focus on homogeneous bioclimatic areas, which are ecologically

17 meaningful in contrast to whole land cover classes and we will therefore refer to the areas described

18 above as "biomes" instead of land cover classes. Also, we retain a suitable number of pixels per

19 biome for the derivation of the phenological models (Table 1, column 6), although there are only

20237 pixels in DNF and about 169 in DBF. There are, however, only 245 and 233 pixels in land

21 cover class DNF and DBF respectively in the northern Hemisphere; the reduced number of pixels in

22 DBF results from the exclusion of Yukatan.

\subsection{Phenological models for leaf budburst}


1 Four models describing the time of budburst, $t_{b b}$ (see Table 2), of temperate plants in response to

2 temperature have typically been used in the literature: the Spring Warming Model, the Sequential

3 Model, the Parallel Model and the Alternating Model (Chuine et al., 1998; Hanninen et al., 1990;

4 Kramer, 1996; Murray et al., 1989; Sarvas, 1974). In all models budburst occurs when GDD

5 exceeds a threshold $F^{*}$, i.e. $t_{b b}=t_{F^{*}}$. These four models reflect different assumptions about the

6 ecophysiology of the budburst process.

7 - In the Spring Warming Model (SWM) forcing units for budburst, $R_{f}(t)$, are accumulated from a

11 which consider a chilling effect, with this model to evaluate the importance of including

12 chilling in green-up models. .

13 - The Sequential Model postulates that budburst is not possible at all until dormancy has been

14 broken by a certain amount of chilling, the chilling requirement, $C^{*}$.

15 - The Parallel Model weakens the assumptions of the Sequential model; the effectiveness of the

16 temperature forcing is only reduced if the chilling requirement is not fulfilled: chilling, $R_{c}(t)$, and $R_{f}(t)$ accumulate in parallel, but chilling states below $C^{*}$ reduce the rate of forcing. Alternating Model. 
1 In all models the temperature thresholds for the accumulation of chilling or forcing units $\left(T_{c}, T_{f}\right)$,

2 are assumed to be constant and species specific. However, models may reduce the effectiveness of

3 chilling or forcing temperatures, i.e. reduce $R_{c}(t)$ or $R_{f}(t)$, above or below these thresholds,

4 respectively (Chuine et al., 1998; Kramer, 1996; Murray et al., 1989).

5 Since many authors found an exponential relationship between $F^{*}$ and $S_{c}(t)$ (Chuine et al., 1998, 6 1999; Heide, 1993; Murray et al., 1989; Myking, 1997; Zhang et al., 2004) we focus here on the

7 AM, as the other models do not allow for the frequently observed relationship between the amount

8 of warming and chilling required for budburst.

9 We modify the AM, $F_{1}$, and introduce an explicit dependence on the local mean annual or mean

10 winter temperature (Table 2 , functions $\left.F_{i}, i=2, \ldots, 5\right)$, and explore them together with the $\operatorname{SWM}\left(F_{0}\right)$

11 and $\mathrm{AM}\left(F_{1}\right)$ across our biomes for the northern hemisphere. The inclusion of a temperature mean

12 allows in particular explicitly capturing changes in phenology within single biomes in the model.

13 The SWM is a special case of all other models if the chilling requirement, or the effect of annual

14 mean temperature on the bud burst threshold is set to zero.

15 Through this hierarchy of models we explore whether the inclusion of chilling improves the green-

16 up prediction using the SWM as a reference model. We evaluate through the modifications $\left(F_{i}\right.$,

$17 i=2, \ldots, 5)$ of the standard AM, $F_{1}$, whether the inclusion of provenance, as reflected by local mean

18 annual temperatures (previous January to January mean), $T_{a}$, or mean winter (November,

19 December, January) temperature, $T_{w}$, improves the models. Note that, according to Taylor's

20 Theorem model 3 (function $\mathrm{F}_{3}$ ), is the first order approximation of any model that assumes a

21 (reasonably) smooth dependence of the coefficients in $F_{1}$ on $T$. In other words $F_{3}$ is the first order

22 approximation of any model of the form: $F(t)=a(T)+b(T) \cdot \exp \left(-c(T) \cdot \mathrm{S}_{\mathrm{c}}(\mathrm{t})\right)$ with regular a $(\mathrm{T})$,

$23 \mathrm{~b}(\mathrm{~T})$, and $\mathrm{c}(\mathrm{T})$. Thus, evaluating model 3 in fact evaluates to first order any model that uses

24 temperature dependent coefficients in $\mathrm{F}_{1}$.

\subsection{Model calibration}


1 Models are parameterized by least squares. We first fit all six models $F_{0}-F_{5}$ (Table 2) to all sets of

2 green-up dates obtained from the four methods a)-d). GDD and NCD at the time of green-up and $T_{x}$

$3(x=a, w)$ for each of the 12 years $(1984-1995)$ and each biome. This results in 480 cases per biome.

4 To limit the number of parameters and ensure that (first and second) derivatives of the models exist,

5 we fix the starting dates $\left(\mathrm{t}_{\mathrm{C} 0}\right.$, and $\left.\mathrm{t}_{\mathrm{F} 0}\right)$ for $S_{c}(t)$ or $S_{f}(t)$ to the first of November and the first of

6 January, respectively (Murray et al., 1989). We also set the threshold temperatures for chilling and

7 forcing to zero, $T_{c}=T_{f}=0$ (Heide, 1993; Myking, 1997; Zhang et al., 2004). The functions $F_{i}$,

$8 i=0, \ldots, 5$, then depend only on the parameters $a_{j}, b_{k}$, and $c_{l}$, and can be differentiated with respect to

9 all their parameters. If we would allow start dates and thresholds to vary as well, then the

10 differentials are climate dependent and the recalculation of the derivatives requires larger

11 computational resources. We use a varpro algorithm for nonlinear least squares (netlib.org), with a

12 gradient method using derivatives, and for comparison with (Chuine et al., 1998) a simulated

13 annealing implementation (Press et al., 2002).

15 The models were calibrated on one year of data and on the entire record of 12 years. Calibrating the 16 models on a single year of data however leads to overfitting, i.e. the models are specific to that one 17 year. Consequently the models cannot portray well a more generalized relationship reflecting the 18 conditions in other years and have reduced predictive power (Smith, 1996). The "best" model 19 would be obtained by using all available data, but this would preclude evaluation of the model. A 20 method that avoids overfitting and allows assessment of predictive power of a model is the leave21 one-out (LOO) cross-validation (CV) (Allen, 1974) which we use here. We partition the data into 2212 sets of 11 years to calibrate the model and 1 year for validation by leaving out each year once.

23 All four models are calibrated and validated on these 12 sets. The LOO CV method avoids 24 overfitting $(\mathrm{Ng}, 1997)$, reduces bias introduced by relying on any one particular division of the data 25 (Allen, 1974) and yields uncertainty estimates for the parameters. 
2 To evaluate differences between any two sets of modelled GDD data or green-up dates from NDVI

3 or the different functions $\mathrm{F}_{0}-\mathrm{F}_{5}$ we use the paired two sample Wilcoxon rank sum test, with the Null

4 hypothesis, $\mathrm{H}_{0}$, of equal means, to test whether the modelled means are the same. To determine

5 whether there is a difference in the distribution of the modelled data between any two of the $\mathrm{F}_{1}-\mathrm{F}_{5}$

6 we use in addition the Kolmogorov-Smirnov test, with $\mathrm{H}_{0}$ of equal distributions. Tests are

7 conducted using the implementations in R (R Development Core Team, 2005).

\section{3. Results}

\subsection{Green-up dates from remote sensing}

10 The curvature methods b) and d) detect green-up when large fractions of pixels are actually still

11 snow covered (Table 3, Table 4). This leaves too few pixels for deriving green-up models that are

12 meaningful for whole biomes. Detection of green-up during the snow free period can be forced, e.g.

13 by excluding snow covered times, or by using NDVI values from snow free times to fill the snow

14 covered period for evergreen biomes. This will lead, however, to other artefacts; any function fitted

15 to the NDVI data filled with a recent snow free value will still have its maximal curvature very

16 close to the time of snow melt (Figure 4). We therefore focus our analysis methods a) and c) that are

17 less sensitive to snow artefacts.

19 Method a) of (White et al., 1997) detects green-up 10-40 days later than the curvature methods

20 (Table 5) and significant fractions of pixels are snow free according to the snow cover data (Table

21 4). Thus the significant increases in NDVI detected by method a) reflect increases in leaf area

22 index, LAI, rather than changes in snow cover. 
1 Compared to method a) method c) indicates 8-10 days later green-up except for DBF where the

2 mean green-up times are only a day apart (Table 4).

4 To evaluate the impact of the smoothing by the Fourier adjustment and Interpolation of the FASIR

5 corrections on the inferred time of green-up we determined green-up using the viASR data. Method

6 a) detects green-up within five days of the FASIR data for DNF, DBF, MixF and Wdld. For ENF

7 the average green-up based on the viASR data is 11 days earlier. This is due to the fact that the for

8 ENF the October values are used in the FASIR winter data. Thus the minimum (winter) NDVI

9 value for the FASIR data is larger than for the viSAR data and therefore the half range is reached

10 later in the year. The 11 days earlier green-up implies, however, that more pixels will be affected by

11 snow cover at green-up (compare to the green-up dates from method b). We consider therefore the

12 green-up derived from the FASIR data to be more realistic for ENF. For OpSh the viASR data lead

13 to 15 days later estimates of green-up for the snow free pixels and 9 days later estimates of green-up

14 for all pixels. This results from the fact that the viASR data comprise many points in the far north

15 which have only data from the late spring until autumn. These points have either been excluded

16 from the FASIR data or they have been filled with low values. The latter leads to detection of an

17 earlier green-up with method a) on the FASIR data. Again we consider green-up dates obtained

18 with the FASIR data to be more appropriate.

The mean green-up time of the region $35^{\circ} \mathrm{N}-75^{\circ} \mathrm{N}$ determined via method a) shows a trend of about

21 four days to earlier times for the 12 years considered here (-0.36 d/a for 1986-1995), which is well

22 in line with in situ observations (Menzel, 2000; Menzel and Fabian, 1999), e.g. 0.3-0.5 days per

23 year in Europe from in situ observations in phenological gardens (Menzel, 2000), and other

24 evaluations of remote sensing observations.

\subsection{Calibration of the phenological models}

Page 17 
1 Functions $\mathrm{F}_{2}, \mathrm{~F}_{4}$ and $\mathrm{F}_{5}$ (see Table 2) turn out to be difficult to calibrate. The varpro algorithm

2 virtually always fails for function $\mathrm{F}_{4}$, for all biomes and all years, mostly due to ill-conditioning. $\mathrm{F}_{5}$

3 can only be fitted in about half of the cases and $F_{2}$ in half to two thirds. $F_{0}$ can always be fitted

4 while the fitting of $F_{1}$ and $F_{3}$ fails only in about a sixth of the cases (Table 5).

5 The mean 1984-1995 residuals of the GDD fits are in general largest for $\mathrm{F}_{0}$ and smallest for $\mathrm{F}_{5}$, as

6 expected from the number of parameters. The residuals for $\mathrm{F}_{4}$ are typically the second largest,

7 because an optimal parameter set could not be found for a large number of cases; so the model is

8 not appropriate for describing the green-up dates despite its complexity. The fits of $F_{2}$ and $F_{3}$ have

9 very similar residuals, which are somewhat smaller than the ones of $F_{1}$ and in general only a little

10 larger than the ones of $\mathrm{F}_{5}$ (Table 5). Kolmogorov-Smirnov and Wilcoxon rank sum tests suggest

11 that except for three cases there is no significant difference $(\mathrm{p}<0.05)$ between the residuals of the

12 fits of $F_{2}$ and $F_{3}$, and for these three cases $F_{3}$ allows the better fits. Where the tests suggests a

13 difference in the fits between functions $\mathrm{F}_{3}$ and $\mathrm{F}_{5}$, the difference is small and there are only 2-5

14 years for which $\mathrm{F}_{3}$ and $\mathrm{F}_{5}$ could both be fitted making the tests uncertain and potential gains from

15 using $\mathrm{F}_{5}$ small.

17 Using simulated annealing to determine the models gives only slightly different results. Again, the 18 residuals for $F_{0}$ are larger than those from $F_{1}, F_{2}$, and $F_{3}$, but residuals for $F_{5}$ remain large which 19 probably reflects that no unique solution could be found for the large parameter space. Again, $\mathrm{F}_{4}$

20 either results in large residuals or the algorithm fails. While with simulated annealing the residuals 21 for $\mathrm{F}_{3}$ are consistently smaller than the ones for $\mathrm{F}_{1}$ and $\mathrm{F}_{2}$, there is most likely again no significant 22 difference between $\mathrm{F}_{2}$, and $\mathrm{F}_{3}$.

24 Trading simplicity and appropriateness versus accuracy of the models suggests disregarding $\mathrm{F}_{2}, \mathrm{~F}_{4}$ 25 and $\mathrm{F}_{5}$ (Table 5). The NCD-GDD relationships were appropriately described with $\mathrm{F}_{0}, \mathrm{~F}_{1}$ and $\mathrm{F}_{3}$; 
1 controlled experiments also suggest that a single exponential relationship is appropriate for

2 modelling these relationships (Hunter and Lechowicz, 1992; Kramer, 1994; Murray et al., 1989)

3 We conclude that any dependence on the mean winter or annual temperature can be well described

4 by using temperature dependent parameters in $F_{1}$, which leads to $F_{3}$, and that additional terms, as in

$5 \quad \mathrm{~F}_{2}, \mathrm{~F}_{4}$ and $\mathrm{F}_{5}$, are redundant as they do not lead to improved models.

\subsection{Statistical analysis}

8 Calibrating the models on single years leads to overfitting of the models and to low predictive

9 power. For all methods, biomes and models the 12-year mean error of the green-up predictions

10 more than $50 \%$ higher than the error for the year on which the model was calibrated. The prediction

11 error increases if the calibration error decreases - the better the reproduction of the calibration data

12 the worse the generalization to other years.

13 The mean prediction errors from LOO CV varpro calibrations (see 2.5), i.e. the errors on the years

14 not used for calibration, are nearly as small as the mean errors of the models calibrated for one year

15 on the calibration data (Table 6). In other words the general models obtained from calibration on 11

16 years of data have a mean prediction error approaching the mean error of overfitted models on the

17 one calibration year. Also, the LOO CV approach results in acceptable models where these models

18 cannot be determined from single years of data (see DNF in Table 6).

20 The biome mean absolute calibration errors of the GDD at green-up for the 12 years 1984-1995

21 from $\mathrm{LOO} C V$ are significantly larger for $\mathrm{F}_{0}$ than for $\mathrm{F}_{1}$ for all biomes as indicated by a paired

22 Wilcoxon signed rank test (all p-values $<0.025$ ). This shows that including a chilling requirement

23 leads to better model calibration. 
1 The calibration errors of the GDD at green-up of $F_{3}$, using $T_{a}$, is significantly smaller than the one

2 for $\mathrm{F}_{1}$ for biomes ENF, DBF, and Wdld (all p-values < 0.05). For OpSh the p value for 3 years is

3 large leading to a 12 year mean of $p=0.11$. Using $T_{w}$ with model $F_{3}$ is not significantly better than

4 using $\mathrm{T}_{\mathrm{a}}$ for biomes DBF, Wdld and OpSh. For biome ENF using $\mathrm{T}_{\mathrm{w}}$ leads to smaller calibration

5 errors and for MixF $F_{3}$ can be fitted, which was not possible with $T_{a}$, with smaller errors than for $F_{1}$.

6 Do for the biomes ENF, DBF, MixF, Wdld and OpSh considering temperature dependent

7 parameters reduces the calibration error compared to constant parameters, even when a chilling

8 requirement is included.

10 The prediction errors for the green-up date show that model $F_{1}$ gives significant lower errors than

11 model $\mathrm{F}_{0}$ for ENF, DNF, DBF, MixF with mean $\mathrm{p}<0.05$, for Wdld with $\mathrm{p}<0.1$, and OpSh with

$12 \mathrm{p}<0.17$; the mean $\mathrm{p}$ for OpSh is dominated by one $\mathrm{p}$ value for one year close to 1 .

13 Model $F_{3}$ with $T_{a}$ is significantly better $(p<0.05)$ than $F_{1}$ for OpSh and Wdld as well as ENF if one

14 or two years with p close to one are excluded. For DBF the prediction error from $\mathrm{F}_{3}$ is not

15 consistently smaller than that from $F_{1}$. For ENF model $F_{3}$ with $T_{w}$ is significantly better than $F_{1}$

$16(\mathrm{p}<0.05)$. For MixF for all but 3 years the prediction errors of model $\mathrm{F}_{3}\left(\mathrm{~T}_{\mathrm{w}}\right)$ are significantly smaller

17 than the ones of $F_{1}$.

19 The fits from method c) do not allow significantly more accurate predictions than the ones from method a) except in DNF and OpSh. These are the biomes where the green-up detected by the

21 methods is most different (Table 4). Any higher accuracy of method c), however, might just simply result from the climate condition of the method as any regularity of year to year temperatures will

23 increase its predictive accuracy. We therefore suggest that the method tends to predict when the 24 running mean temperature reaches $5^{\circ} \mathrm{C}$ and not so much green-up. 

warming projections

3 Mean observed green-up (1986-1995) according to method a) occurred at day 144 compared to a

4 prediction of day 145.9 simulated using our best models (Table 8) and the GSWP2 temperatures.

5 Simulating green-up with the temperatures from the $20^{\text {th }}$ century climate model control run leads to

6 a mean green-up day of 146.6. The simulated green-up times are consistently slightly later $(\sim 2$

7 days), as indicated by the 10 year means, but interannual variability is very similar between

8 observations and simulations (Figure 6). The latitudinal distribution of observations and simulations

9 agrees well, with the exception of the green-up simulated using the climate model temperatures for

10 the region $35^{\circ} \mathrm{N}-42^{\circ} \mathrm{N}$ where the green-up is estimated quite early (Figure 7). As expected from the

11 previous sections our best models, which all include a chilling requirement, predict an earlier and

12 therefore more appropriate time of green-up for the $20^{\text {th }}$ century climate simulation than the spring

13 warming models, $\mathrm{F}_{0}$, we also determined (Figure 8).

14 The simulated green-up under the B1 scenario of climate change in 2050-2060 is on average 4-5

15 days earlier than the green-up simulated with the $20^{\text {th }}$ century control run $1985-1996$ (Figure 8 ). The

16 A2 climate leads to 1-2 days earlier green-up than the B1 climate. The spring warming models

17 suggest an even larger advance of green-up of 7-9 days in the 2050s for the A2 scenario. This

18 indicates that chilling requirements are no longer fulfilled in the A2 scenario and the warming

19 cannot compensate for the loss of NCD required for green-up.

20 Regionally, larger changes in the green-up data (up to nearly two weeks earlier) are predicted in 21 central Europe, Russia, Northern Siberia and the Rocky mountains (Figure 9).

\section{Discussion}


1 Our results indicate that method a) of (White et al., 1997) is preferable over the other methods

2 considered to obtaine green-up estimates from coarse scale AVHRR - NDVI data. Functions $F_{1}$ for

3 DNF and DBF, $\mathrm{F}_{3}\left(\mathrm{~T}_{\mathrm{w}}\right)$ for ENF and MixF and $\mathrm{F}_{3}\left(\mathrm{~T}_{\mathrm{a}}\right)$ for the Wdld, and OpSh provide the best

4 models for prediction of the time of green-up. $\mathrm{F}_{0}$ does, however, provide a nearly as good a model

5 for DNF as $\mathrm{F}_{1}$.

6 Zhang et al. (2003) determined a generic relationship between NCD and GDD for northern forests

7 using one year of data with a variation of method b). EVI affected by snow cover, as indicated by

8 the QA flags, are substituted with the most recent snow free value. Our results indicate that the

9 green-up dates determined by this methods are influenced by the snow melt time (as discussed in

10 3.1). Moreover, we expect that their model cannot be transferred to the analysis of other years

11 without further calibration. Moulin et al. (1997) also found that their curvature based method should

12 not be used when there is a significant amount of snow cover.

13 Method c) is strongly determined directly by climate variations and was less successful in

14 predicting variations in vegetation activity. It relies on a constant relationship of climate properties

15 and vegetation activity and is likely to break down when this relationship changes, e.g. due to

16 climate change. Moreover, method c) does not lead to significantly more reliable models than

17 method a) (see 3.3). We therefore will not consider it further.

18 Overall we prefer method a). It resulted in small residuals and reproduced the trend to earlier

19 observed green-up over the time period 1984-1995 in line with in situ observations. The method

20 provides reasonable estimates for the time of green-up; the green-up dates determined with this

21 method are only 10-20 days after snowmelt. This estimate more or less agrees with the time of

22 major leaf expansion (Marell et al., 2006; Pornon and Lamaze, 2007 ). (White et al., 2009)

23 compared of 10 methods to detect green-up from RS and also found that our method a)

24 (Midpoint $_{\text {pixel }}$ of (White et al., 2009)) was one of the only two that was well correlated to start of

25 spring (SOS) measures and resulted in a low bias. They also find that overall NDVI based SOS 
1 estimates best match with observations of "first leaf appearance". (Shutova et al., 2006) shows a

2 high correlation to in-situ phenology data across Fennoscandia with results from their method to

3 detect the start of the growing season, which is very similar to our method a).

4 Our model fitting indicates that a chilling requirement present in the all temperate and boreal

5 biomes we considered

7 The fact that the AM $\left(\mathrm{F}_{1}\right)$ model accurately predicts green up in biomes DNF and DBF suggests that 8 there is no significant adaptation of the phenology of green-up to the local mean temperatures. This

9 finding is supported by studies on European tree species: Kramer's (1995) study of seven European

10 tree species found no significant difference of leaf unfolding times between local and transplanted

11 individuals of the same species from different latitudinal ranges. Chuine et al. (1998) also found

12 that only one out of eight European deciduous broadleaf species showed a limited local adaptation

13 of its flowering time. This implies that it is not justified to include local adaptations of phenology

14 into the model for these biomes.

15 For biomes ENF, MixF, Wdld, and OpSh, which cover larger and diverse areas, our model fitting

16 finds significant adaptation of phenology and/or species to the local climate, as the models improve 17 when mean annual or winter temperature are included.

19 The error spread in green-up date from our models compare well with results of other authors. For example (Picard et al., 2005) find RMSE of 5-8 days for their budburst models for one limited

21 region in Siberia, which should be compared the RMSE of our model predictions of 3.8-8.4 days for DNF and 8.5-14.3 days for OpSh. (Rötzer et al., 2004) find MAE of 4.7 and 4.9 days for their 23 models for the leafing in south-east Germany of Quercus robur and Fagus sylvetica, respectively, 24 which should be compared to our MAE of about 9.6 days for DBF; and MAE of 4.4 and 5 days for the May shoot of Picea abies and Pinus sylvestris which should be compared to our MAE of about 
$1 \quad 10$ and 8 days for ENF and MixF, respectively. Since our models apply for whole northern

2 hemisphere biomes, instead of single species or limited regions, for which much better models

3 should be expected, our results are very acceptable. They also compare favourably with the errors in

4 a RS based analysis by (Botta et al., 2000) who found RMSE in the range of 10-20 days, depending

5 on the biome).

7 Calibrating models with small data sets, e.g. just one year of data or a small region (e.g. (Chuine and Cour, 1999; Kaduk and Heimann, 1996; Picard et al., 2005), leads to overfitted models which

9 have limited predictive power, underestimate the uncertainty for the calibration year, and overestimate the prediction error (Smith, 1996). For example, when (Picard et al., 2005) fit their

11 model separately to four years, the overfitting is evident from the four very different parameter sets 12 they obtain (e.g. their $\mathrm{F}^{*}$ varies from 23 to 269 ), which might not even be physiologically

13 reasonable. $\mathrm{F}^{*}$ should reflect the warming requirement and one would not expect such a large 14 variation from year to year. If Picard et al. (2005) calibrate their model with all four years they 15 obtain ecologically reasonable values of $4.1^{\circ} \mathrm{C}$ for $\mathrm{T}_{\mathrm{b}}$, and 65 for $\mathrm{F}^{*}$. Parameter uncertainty and 16 prediction error, however, remain unclear.

17 Contrary to this, with LOO CV we obtain well supported parameter values with an uncertainty 18 range (Table 7). Our parameter estimates are very consistent between calibrations, as each relies on 1911 years, and should therefore reflect mainly the phenological processes and less so any interannual 20 variability. The parameter range from the LOO calibrations provides an estimate of the uncertainty 21 in the parameters obtained from the calibration using all 12 years of data.

22 Moreover we obtain a robust estimate of the prediction error. Due to the continuity of the error as a 23 function of the parameters of the models one may assume that the mean prediction error from the 12 24 LOO CV runs reflects the prediction error of the models using all 12 years for calibration. 
1 The simulated interannual variability of the time of green-up 1986-1995 using the GSWP 2 as well

2 as the $20^{\text {th }}$ century simulated control temperatures as well as latitudinal variability are quite similar

3 to the variability of the observations (Figure 6). This gives confidence that the modelled sensitivity

4 is realistic and the models can indicate the sensitivity to future climate change.

5 The fact that our best models all include a chilling requirement and that spring-warming only

6 models indicate a later, less accurate, green-up suggest that green-up is best described by

7 accounting for chilling.

9 The dependencies of the model parameters on the mean temperatures of a previous period act in a

10 way such that relatively responses become similar. For example the GDD threshold for OpSh

11 decreases as the mean annual temperature decreases. This allows similar accumulation of GDD for

12 relatively cold and warm regions within the same biome. This is somewhat analogue to Linsser's

13 hypothesis (Linsser, 1867) that a growth stage would be reached at some constant fraction of the

14 annual heat sum.

16 The change in green-up timing from the 1990s to the 2050s for the northern biomes is potentially

17 only about five days on average (Figure 8), which is modest compared to the change over the last 2-

183 decades. The spring warming models indicate a much earlier green-up in the future even though

19 they simulated a later green-up for the past decades than the models including a chilling

20 requirement.

21 This shows that the limited advance of green-up in the future is due to the opposing effects of

22 climate warming on warming and chilling with warming increasing GDD experienced by the biota

23 but also reducing the chilling, increasing the GDD required for green-up.

24 Regionally, however, still an up to 15 days earlier green-up is predicted (Figure 9).

\section{5. Conclusions}


1 White et al. (1997) proposed a method to detect green up from satellite NDVI data of (mostly) snow

2 free conditions. We found that this method leads to better results than several RS green-up detection

3 methods that cannot distinguish between green up and the end of snow melt.

4 We used the satellite based estimates of green up to derive phenological models to predict green up

5 from climate data for the northern hemisphere north of $45^{\circ} \mathrm{N}$. Phenological models were derived

6 for ENF, DNF, MixF, and Wdld, north of $30^{\circ} \mathrm{N}$ for DBF and north of $50^{\circ} \mathrm{N}$ for OpSh, and these

7 models are suitable for inclusion into climate models

8 The best model estimates for predicting green-up from chilling and growing degree days have

9 acceptable prediction errors between 5 and 10 days (Table 8) as estimated from LOO CV which

10 compares very favourably with other studies.

11 To our knowledge this study is the first one using LOO CV for error estimation of large scale

12 phenology models; (Häkkinen, 1999) used it for Betula Pendula only. Moreover, we not only

13 estimate the prediction error, but also obtain a range indicating the uncertainty of the model

14 parameters from LOOCV. Using multiple years and LOO CV is critical to obtain stable models that

15 are not overfitted and generalize well.

16 Determining phenology models requires observations that cover a broad range of climatic

17 conditions as otherwise any relationship between warming and chilling requirement might not be

18 reflected in the data. For biomes covering large areas models taking into account a local mean

19 temperature allows a slightly, however significantly, smaller prediction error. This suggests that

20 phenology comprises an element of adaptation of vegetation to the local climate.

22 Our experiments with our best models, which all include a chilling requirement, and the spring-

23 warming models using temperature predictions climate model simulations show that the inclusion

24 of a chilling requirement in phenology models changes projections of green-up by several days.

25 Spring warming models without a chilling requirement predict too late green-up for the current 
1 climate and overestimate the advance of green-up times in future climates. To assess the effect of a

2 changing climate on green up, the balance has to be considered between, increasing GDD resulting

3 in earlier green-up, and decreasing chilling, increasing the GDD requirement.

\section{Acknowledgements}

5 Parts of this work were carried out while Jörg Kaduk was on sabbatical leave from the University of

6 Leicester at the University of Wales, Swansea (now Swansea University). Jörg Kaduk received a

7 visiting scientist grant from the NERC centre of excellence CLASSIC. The manuscript benefited from discussions with our colleagues Dr. Susanne Hoche, Dr. Sue Page and the suggestions of two anonymous reviewers.

\section{References}

Allen DM (1974) The relationship between variable selection and data augmentation and a method for prediction. Technometrics 16:125-127. Armstrong L, Brodzik MJ (2002) Northern Hemisphere EASE-Grid Weekly Snow Cover and Sea Ice Extent Version 2. National Snow and Ice Data Center, Boulder, CO, USA. Botta A, Viovy N, Ciais P, Friedlingstein P, Monfray P (2000) A global prognostic scheme of leaf onset using satellite data. Global Change Biology 6:709-725. Cannell MGR, Smith RI (1986) Climatic Warming, Spring Budburst and Frost Damage to Trees. Journal of Applied Ecology 23:177-191. Chuine IP, Cour P (1999) Climatic determinants of budburst seasonality in four temperate zone tree species. New Phytologist 143:339-349. Chuine IP, Cour P, Rousseau DD (1998) Fitting models predicting dates of flowering of temperatezone trees using simulated annealing. Plant, Cell \& Environment 21:455-466.

Chuine IP, Cour P, Rousseau DD (1999) Selecting models to predict the timing of flowering of temperate trees: implication for tree phenology modelling. Plant, Cell \& Environment 22:1-13. Dye DG, Tucker CJ (2003) Seasonality and trends of snow-cover, vegetation index, and temperature in northern Eurasia. Geophysical Research Letters 30:58-51-58-54.

Fitzjarrald DR, Acevedo OC, Moore KE (2001) Climatic Consequences of Leaf Presence in the Eastern United States. Journal of Climate 14:598-614.

Freedman JM, Fitzjarrald DR, Moore KE, Sakai RK (2001) Boundary Layer Clouds and Vegetation-Atmosphere Feedbacks. Journal of Climate 14:180-197.

Hall FG, Collatz G, Los S, Brown de Colstoun E, Landis DE (2005) ISLSCP Initiative II. Hanninen H, Hakkinen R, Hari P, Koski V (1990) Timing of Growth Cessation in Relation to Climatic Adaptation of Northern Woody-Plants. Tree Physiol. 6:29-39.

Hansen MC, DeFries RS, Townshend JRG, Sohlberg R (2000) Global land cover classification at $1 \mathrm{~km}$ spatial resolution using a classification tree approach. International Journal of Remote Sensing 21:1331-1364. 
Heide OM (1993) Dormancy release in beech buds (Fagus sylvatica) requires both chilling and long days. Physiologia Plantarum:187-191.

Holben BN (1986) Characteristics of maximum-value composite images from temporal AVHRR data. International Journal of Remote Sensing 7:1417-1434.

Hunter AF, Lechowicz MJ (1992) Predicting the Timing of Budburst in Temperate Trees. Journal of Applied Ecology 29:597-604.

Häkkinen R (1999) Statistical evaluation of bud development theories: application to bud burst of betula pendula leaves. Tree Physiol. 19:613-618.

Hüttich C, Herold M, Schmullius C, Egorov V, Bartalev SA SPOT-VGT NDVI and NDWI trends 1998-2005 as indicators of recent land cover change processes in northern Eurasia. in 2nd

Workshop of the EARSeL SIG on Land Use and Land Cover, Bonn, pp. 336-344.

IPCC (2000) Special Report on Emissions Scenarios. Cambridge University Press, Cambridge, United Kingdom.

James ME, Kalluri SNV (1994) The Pathfinder AVHRR land data set - an improved coarse resolution data set for terrestrial monitoring. International Journal of Remote Sensing 15:33473363.

Kaduk J, Heimann M (1996) A prognostic phenology scheme for global terrestrial carbon cycle models. Climate Research 6:1-19.

Keeling CD, Chin JFS, Whorf TP (1996) Increased activity of northern vegetation inferred from atmospheric $\mathrm{CO}_{2}$ measurements. Nature 382:146-149.

Kramer K (1994) Selecting a model to predict the onset of growth of Fagus sylvatica. Journal of Applied Ecology 31:172-181.

Kramer K (1996) Phenology and growth of European trees in relation to climate change, Landbouw Universiteit Wageningen.

Lawrence DM, Slingo JM (2004) An annual cycle of vegetation in a GCM. Part II: global impacts on climate and hydrology. Climate Dynamics 22:107 - 122.

Linsser C (1867) Die periodschen Erscheinungen des Pflanzen-Lebens in ihrem Verhältniss zu den Wärme-Erscheinungen. . Mem. Acad. Imp. St. Petersbourg (7).

Los SO (1998) Estimation of the ratio of sensor degradation between NOAA-AVHRR channels 1 and 2 from monthly NDVI composites. IEEE Transactions on Geoscience and Remote Sensing 36:206-213.

Los SO, Collatz GJ, Sellers PJ, Malmström CM, Pollack NH, DeFries RF, Bounoua L, Parris MT, Tucker CJ, Dazlich DA (2000) A global 9-year biophysical landsurface data set from NOAA AVHRR data. Journal of Hydrometeorology:183-199.

Los SO, North PRJ, Grey WMF, Barnsley MJ (2005) A method to convert AVHRR normalized difference vegetation index time series to a standard viewing and illumination geometry. Remote Sensing Environment 99:400-411.

Marell A, Hofgaard A, Danell K (2006) Nutrient dynamics of reindeer forage species along snowmelt gradients at different ecological scales. Basic and Applied Ecology 7:13-30.

Menzel A (2000) Trends in phenological phases in Europe between 1951 and 1996. International Journal of Biometeorology 44:76-81.

Menzel A, Fabian P (1999) Growing season extended in Europe. Nature 397:659.

Moulin S, Kergoat L, Viovy N, Dedieu G (1997) Global-scale assessment of vegetation phenology using NOAA/AVHRR satellite measurements. Journal of Climate 10:1154-1170.

Murray MB, Cannell MGR, Smith RI (1989) Date of Budburst of Fifteen Tree Species in Britain Following Climate Warming. Journal of Applied Ecology 26:693-700.

Myking T (1997) Dormancy, Budburst and Impacts of Climatic Warming in Coastal-Inland and Altitudinal Betula Pendula and B. Pubencens Ecotypes. Progress in Biometeorology 12:51-66. Myneni RB, Keeling CD, Tucker CJ, Asrar G, Nemani RR (1997) Increased plant growth in the northern high latitudes from 1981 to 1991. Nature 386:698-702. 
netlib.org Nonlinear least squares by variable projection.

Ng AY Preventing "overfitting" of cross-validation data. in ICML, pp. 245-253.

Picard G, Quegan S, Delbart N, Lomas MR, Le Toan T, Woodward FI (2005) Bud-burst modelling in Siberia and its impact on quantifying the carbon budget. Global Change Biology 11:2164-2176. Pornon A, Lamaze T (2007 ) Nitrogen resorption and photosynthetic activity over leaf life span in an evergreen shrub, Rhododendron ferrugineum, in a subalpine environment New Phytologist 175:301-310.

Press WH, Teukolsky SA, Vetterling WT, Flannery BP (2002) Numerical Recipes Multi-Language Code CD ROM. 2.11 edn. Cambridge University Press, pp. 1 CD-ROM ; 4 3/4 in.

R Development Core Team (2005) R: A Language and Environment for Statistical Computing. R Foundation for Statistical Computing, Vienna, Austria.

Randall DA, Dazlich DA, Zhang C, Denning AS, Sellers PJ, Tucker CJ, Bounoua L, Los SO, Justice CO, Fung I (1996) A revised land surface parameterization (SiB2) for GCMs .3. The greening of the Colorado State University general circulation model. Journal of Climate 9:738-763. Randerson JT, Field CB, Fung IY, Tans PP (1999) Increases in early season ecosystem uptake explain recent changes in the seasonal cycle of atmospheric $\mathrm{CO}_{2}$ at high northern latitudes. Geophysical Research Letters 26:2765-2769.

Rötzer T, Grote R, Pretzsch H (2004) The timing of bud burst and its effect on tree growth. International Journal of Biometeorology 48:109-118.

Sarvas R (1974) Investigations on the annual cycle of development of forest trees. II. Autumn dormancy and winter dormancy. Communicationes Instituti Forestalis Fenniae, p. 101p.

Sellers PJ, Los SO, Tucker CJ, Justice CO, Dazlich DA, Collatz GJ, Randall DA (1996) A revised land surface parameterization ( $\mathrm{SiB} 2$ ) for atmospheric GCMs, part 2. The generation of global fields of terrestrial biophysical parameters from satellite data. Journal of Climate 9:706-737.

Shabanov NV, Zhou L, Knyazikhin Y, Myneni RB, Tucker CJ (2002) Analysis of interannual changes in northern vegetation activity observed in AVHRR data from 1981 to 1994. IEEE Transactions on Geoscience and Remote Sensing 40:115-130.

Shutova E, Wielgolaski FE, Karlsen SR, Makarova O, Berlina N, Filimonova T, Haraldsson E, Aspholm PE, Flø L, Høgda KA (2006) Growing seasons of Nordic mountain birch in northernmost Europe as indicated by long-term field studies and analyses of satellite images. International Journal Biometeorology 51:155-166.

Smith M (1996) Neural Networks for Statistical Modeling. International Thomson Computer Press, Boston.

Sparks TH, Carey PD, Combes J (1997) First Leafing dates of trees in Surrey between 1947 and 1996. The London Naturalist 76:15-20.

Taylor CM, Saïd F, Lebel T (1997) Interactions between the land surface and mesoscale rainfall variability during HAPEX-Sahel. Monthly Weather Review 125:2211-2227.

Van den Hurk BJJM, Viterbo P, Los SO (2003) Impact of leaf area index seasonality on the annual land surface evaporation in a global circulation model. Journal of Geophysical Research 108:ACL 5-1 - ALC 5-9.

White MA, de Beurs KM, Didan K, Inouye DW, Richardson AD, Jensen OP, O'Keefe J, Zhang G, Nemani RR, van Leeuwen WJD, Brown JF, de Wit A, Schaepman M, Lin XM, Dettinger M, Bailey AS, Kimball J, Schwartz MD, Baldocchi DD, Lee JT, Lauenroth WK (2009) Intercomparison, interpretation, and assessment of spring phenology in North America estimated from remote sensing for 1982-2006. Global Change Biology 15:2335-2359.

White MA, Thornton PE, Running SW (1997) A continental phenology model for monitoring vegetation responses to interannual climatic variability. Global Biogeochemical Cycles 11:217-234. Zhang X, Friedl MA, Schaaf CB, Strahler AH (2004) Climate controls on vegetation phenological patterns in northern mid- and high latitudes inferred from MODIS data. Global Change Biology 10:1133-1145. 
1 Zhao M, Dirmeyer PA (2003) Production and Analysis of GSWP-2 Near-Surface Meteorology Data 2 Sets. COLA Technical Report. Center for Ocean-Land-Atmosphere Studies. 


\section{Figure Captions}

3 Figure 1 Schematic representation of the model development (NH: northern hemisphere).

4 Latitudinal restrictions are applied to a land cover map resulting in the delineation of biome areas.

5 The application of a method for detecting green-up on the NH $0.5 \times 0.50$ NDVI data gives NH green-

6 up dates. Determining the climate indices NCD and GDD at green-up and mean temperatures

7 results after restriction to the biome areas in sets of GDD, NCD green-up date and mean

8 temperature data for the biome pixels for 12 years. Applying a calibration method to determine the

9 parameters for the different model forms leads to the green-up models.

11 Figure 2 Distribution of land cover classes North of 30oN from the University of Maryland 12 vegetation classification (Hansen et al., 2000) (see 2.3Error! Reference source not found.).

14 Figure 3 Growing degree days (GDD) and number of chilling days (NCD) at leaf out in 1984 according to method a) in biome 5. Small grey crosses are pixels north of $45 \mathrm{oN}$ and black plusses are pixels between the equator and $45 \mathrm{oN}$. Figure 4 NDVI , snow covered period and NDVI filled with nearest snow free NDVI value during periods with snow cover for the year 1983 for the pixel of biome ENF centred on $100.25 \mathrm{oE}$ and 59.75oN. Any fit of a function to the filled NDVI will have its maximal curvature very close to the

21 time of snow melt.

Figure 6 Time of green-up for the years 1986-1995 in the areas common to observations and simulations according to the detection by method a) (solid black line) and the derived models using the GSWP2 temperature data (dashed line) and the temperature data from the 20th century control experiment (solid grey line) 
2 Figure 7 Mean time of green-up for the years 1986-1995 averaged over 0.5 degree latitudinal bands

3 in the common areas according to the detection by method a) (solid black line) and the derived

4 models using the GSWP2 temperature data (dashed line) and the temperature data from the 20th

5 century control experiment (solid grey line)

6

7 Figure 8 Time of green-up according to the best models determined (solid black line) and from the

8 spring warming models (short dashed black line) using the temperature data from the 20th century

9 control experiment for the 10 years 1986-1995, from the B1 climate change simulation for 2051-

102060 (solid grey line) and according to the best models determined (dash-dot black line) and the

11 spring warming models (long dashed black line) for the A2 climate change simulation for 2051-

12 2060, respectively.

13

14 Figure 9 Change in the mean time of green-up (negative means to earlier times) from 1986-1995 to

15 2051-2060 as predicted from the simulated $20^{\text {th }}$ century and the A2 scenario temperatures. 


\section{Table Captions}

2 Table 1 Number of pixels in the landcover classes and regions in the UMd land cover data and the

3 number of pixels in the Biomes we consider after the screening detailed in Section 2.3 was applied.

5 Table 2 Notation and formulation of the major types of phenology models (Spring Warming,

6 Sequential, Parallel, and Alternating models) tested in this paper following notation from (Chuine et 7 al., 1998; Hanninen, 1990; Kramer, 1996; Murray et al., 1989). There are some slight variations in 8 the literature.

10 Table 3 Number of grid points in land cover classes 1, 3-6, and 9 for which methods a) - d) detect

11 green-up in 1984 as well as the number of points which are snow free and snow covered according 12 to the snow cover data (Armstrong and Brodzik, 2002) at the time of the detected green-up. Also 13 given the mean number of grid points per biome, i.e. the points remaining after the screening 14 detailed in section 2.3 for which green-up was detected, and the mean number of points 1984-1995, 15 which were snow free at the time green-up was detected.

17 Table 4 Mean day of year of green-up 1984-1995 for the methods a) - d) per biome for the cases 18 (A) when all pixels are considered, and (B) when only those cells are considered which were snow 19 free at the time of the detected green-up.

21 Table 5 Number of successful fits, average and standard deviation of the mean absolute GDD error mean 1984-1995 of the fit to the NCD-GDD relationship with functions F0-F3 to the leaf out dates from method a) considering snow free pixels at leaf out only. 
1 Table 612 year mean average error in green up date for methods a) and c) and functions F0, F1 and

2 F3. The upper eight rows show the mean errors from fitting each function each year for the year

3 they were fitted on. The lower eight rows show the mean absolute prediction errors from Leave One

4 Out Cross Validation (LOO CV, i.e. fitting the functions on 11 years and predicting the 12th). The

5 large errors from some combinations are due to 1-3 outliers where the minimization algorithm

6 could not find a good fit.

7

8 Table 7 Parameters for the selected models from the 12 LOO CV runs for every other year 1984-

91995 and the parameters resulting when the data of all twelve years are used. Years indicate which

10 year was left out from the model calibration. Parameter values are quite similar for all model

11 calibrations. Typically the parameter values resulting from the calibration using all twelve years of

12 data are very close to the values from the LOO CV calibrations.

13

14 Table 8: Definition and error characteristics of the selected models for green-up for the biomes

15 considered here. The models are calibrated using the varpro algorithm and GDD and NCD data

16 from the years $1984-1995$ with $\mathrm{t}_{\mathrm{C} 0}$ and $\mathrm{t}_{\mathrm{F} 0}$ set to the first of November and the first of January,

17 respectively, and the threshold temperatures for chilling and forcing set to zero, $T_{c}=T_{f}=0$. Error

18 data are based on 12 LOO CV runs for the years 1984-1995. 


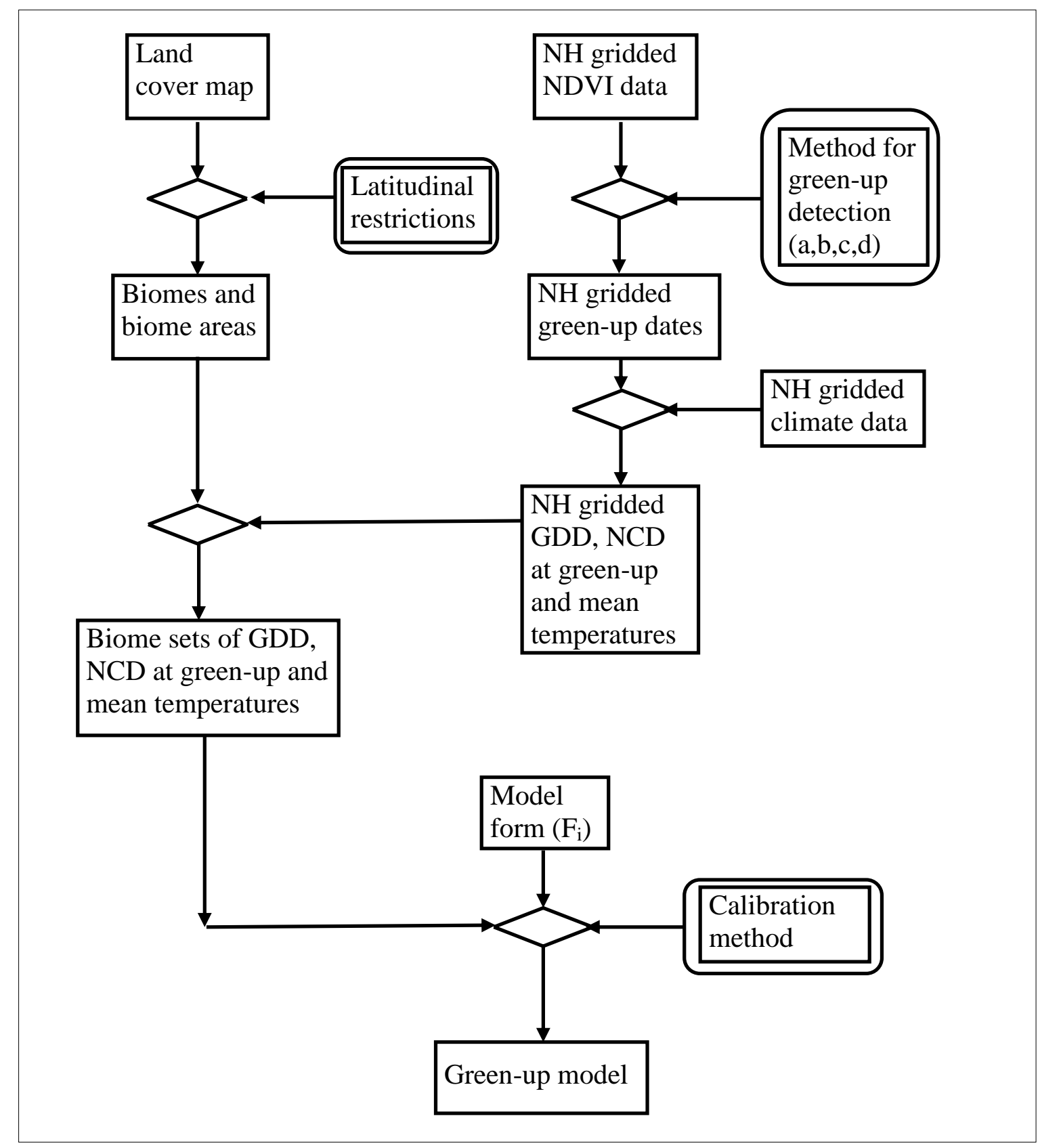

Figure 1 Schematic representation of the model development (NH: northern hemisphere). Latitudinal restrictions are applied to a land cover map resulting in the delineation of biome areas. The application of a method for detecting green-up on the $\mathrm{NH} 0.5 \times 0.5^{\circ} \mathrm{NDVI}$ data gives NH green-up dates. Determining the climate indices NCD and GDD at green-up and mean temperatures results after restriction to the biome areas in sets of GDD, NCD green-up date and mean temperature data for the biome pixels for 12 years. Applying a calibration method to determine the parameters for the different model forms leads to the green-up models. 


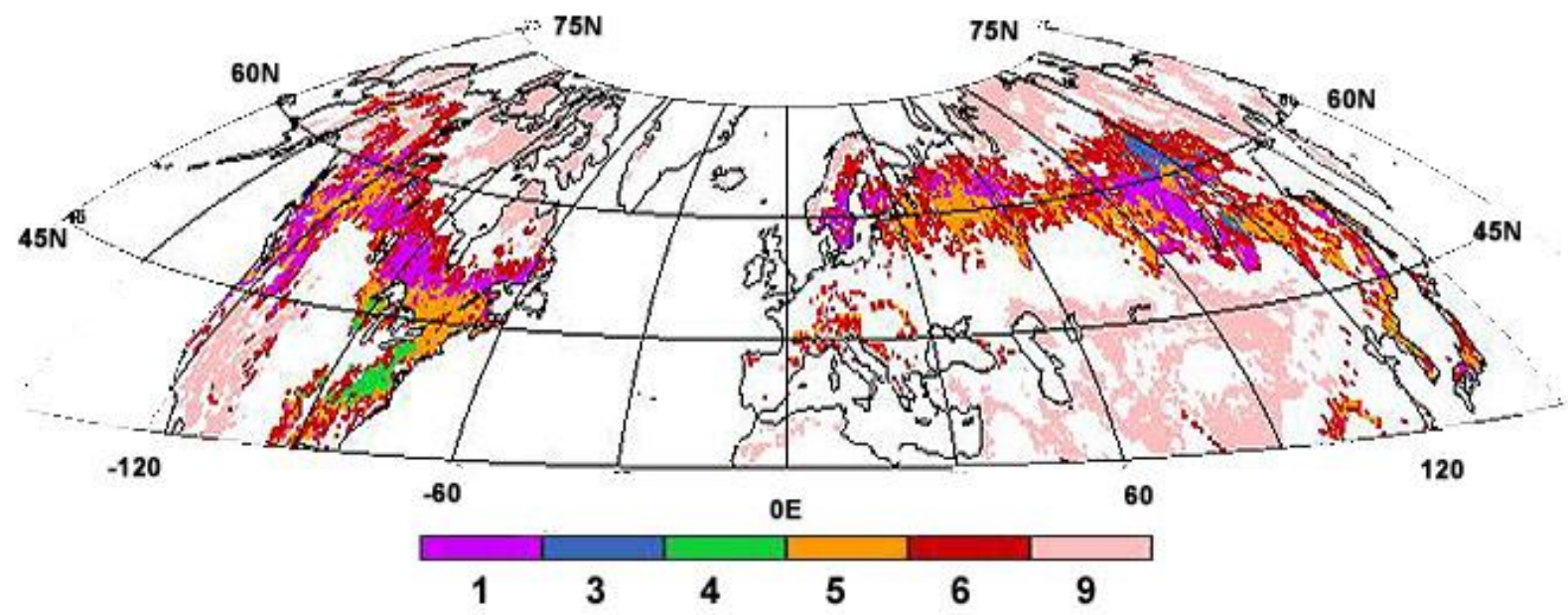

Figure 2 Distribution of land cover classes North of $30^{\circ} \mathrm{N}$ from the University of Maryland vegetation classification (Hansen et al., 2000) (see 2.3Error! Reference source not found.).

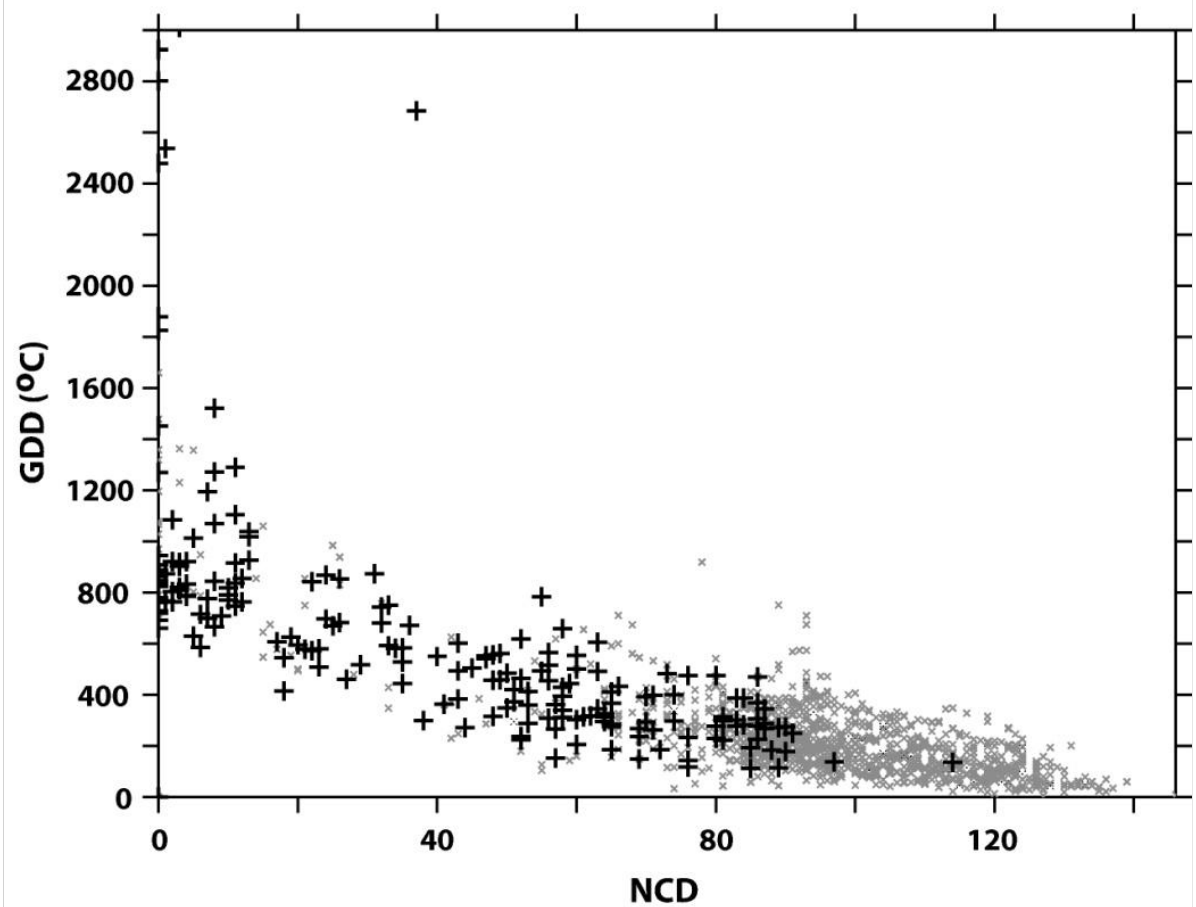

Figure 3 Growing degree days (GDD) and number of chilling days (NCD) at leaf out in 1984 according to method a) in biome 5. Small grey crosses are pixels north of $45^{\circ} \mathrm{N}$ and black plusses are pixels between the equator and $45^{\circ} \mathrm{N}$. 


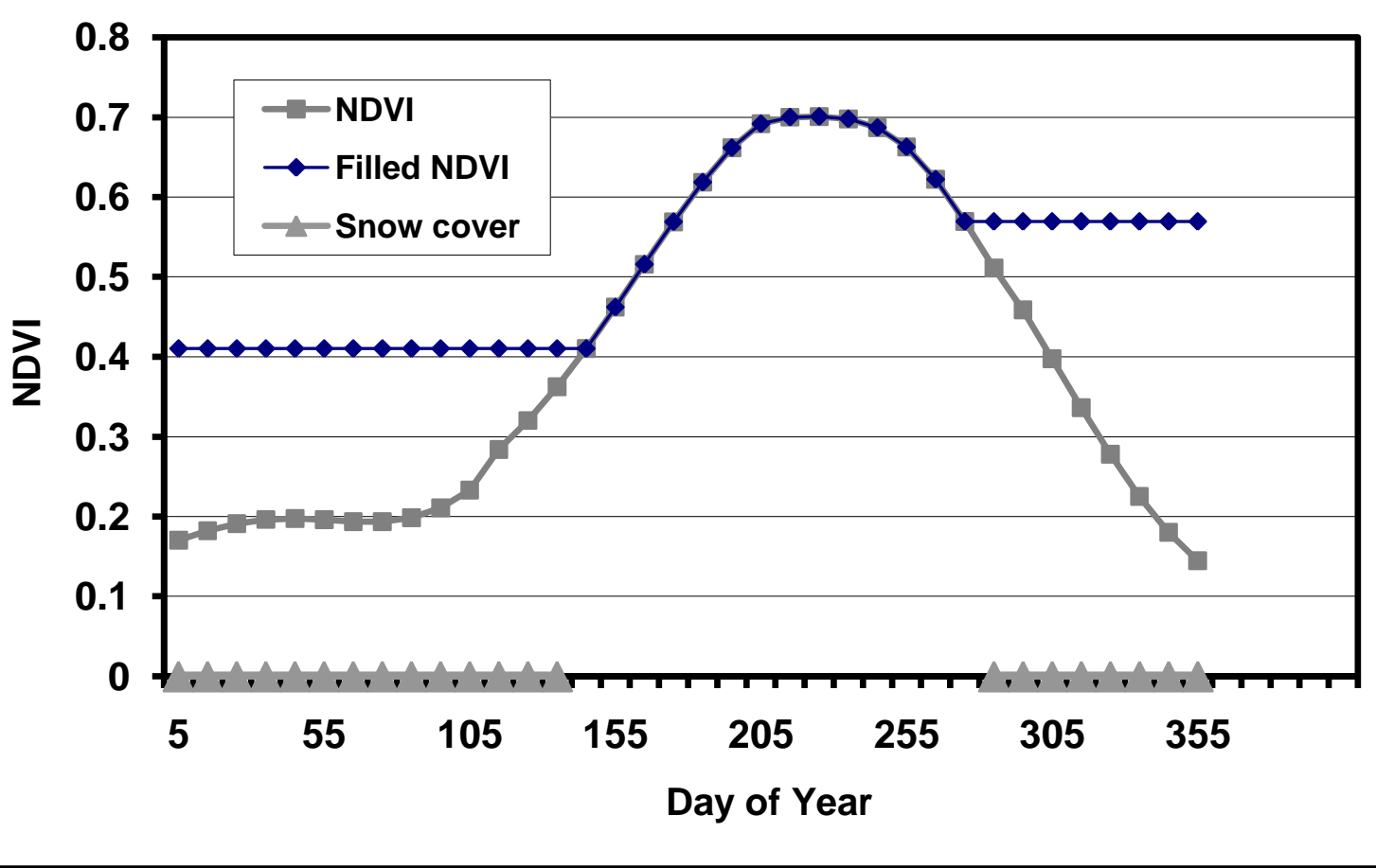

Figure 4 NDVI, snow covered period and NDVI filled with nearest snow free NDVI value during periods with snow cover for the year 1983 for the pixel of biome ENF centred on $100.25^{\circ} \mathrm{E}$ and $59.75^{\circ} \mathrm{N}$. Any fit of a function to the filled NDVI will have its maximal curvature very close to the time of snow melt. 


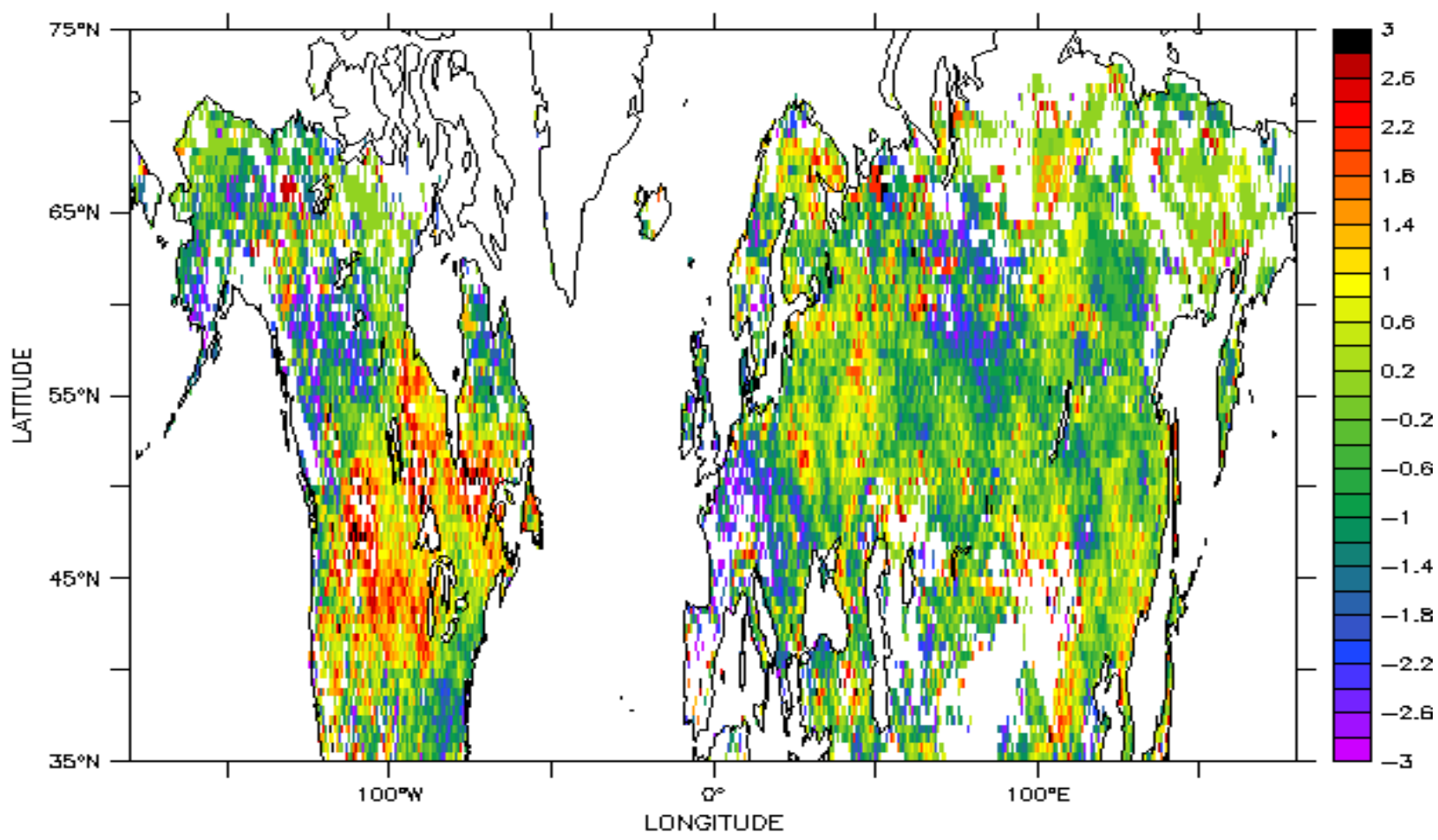

Figure 5 Annual change in the time of green up (days/year) estimated from method a). Negative values indicated an advancement of the time of green up to earlier dates in the year. 


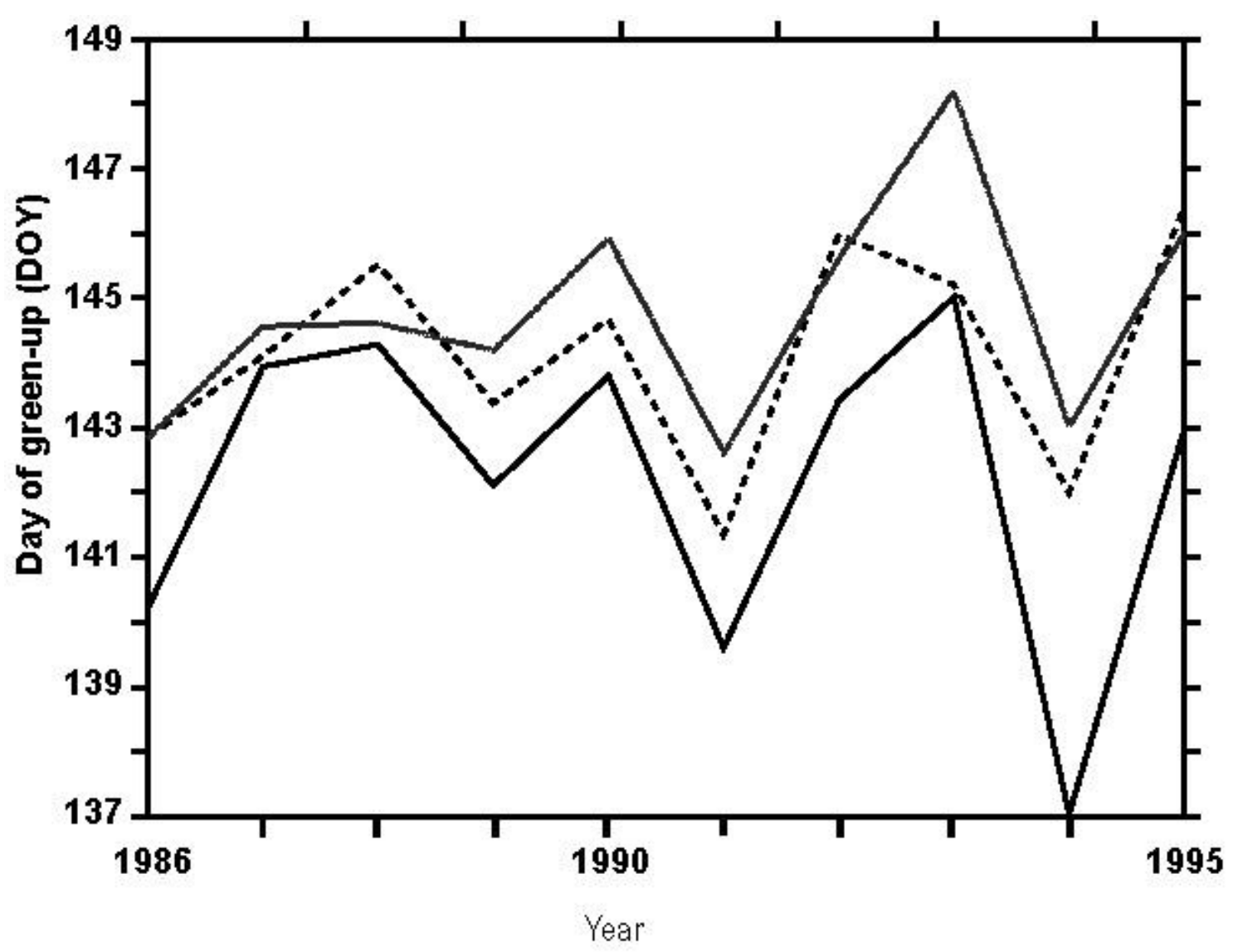

Detected from NDVI -.--n- Simulated, GSWP2

Simulated, clim ate model

Figure 6 Time of green-up for the years 1986-1995 in the areas common to observations and simulations according to the detection by method a) (solid black line) and the derived models using the GSWP2 temperature data (dashed line) and the temperature data from the $20^{\text {th }}$ century control experiment (solid grey line) 


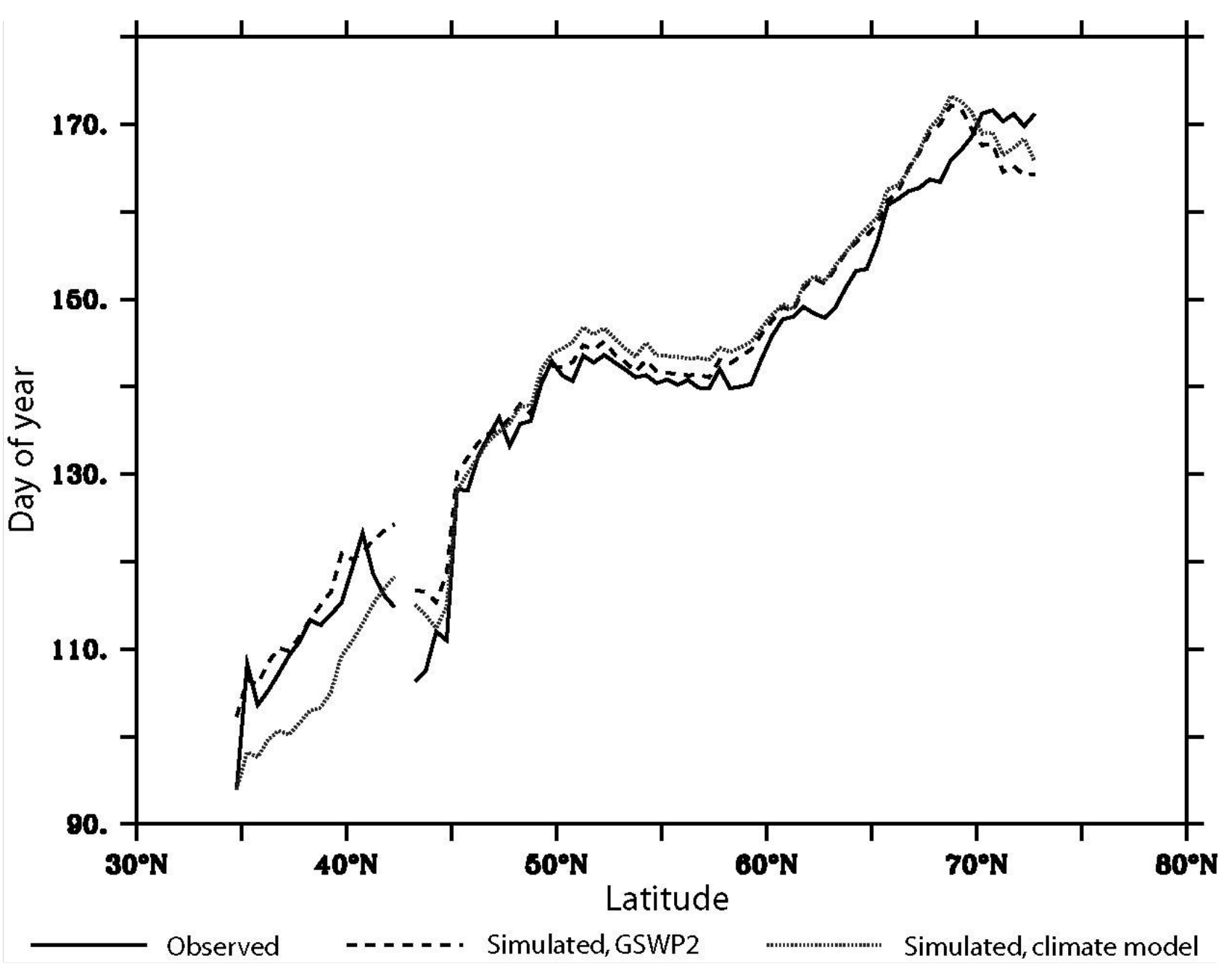

Figure 7 Mean time of green-up for the years 1986-1995 averaged over 0.5 degree latitudinal bands in the common areas according to the detection by method a) (solid black line) and the derived models using the GSWP2 temperature data (dashed line) and the temperature data from the $20^{\text {th }}$ century control experiment (solid grey line) 


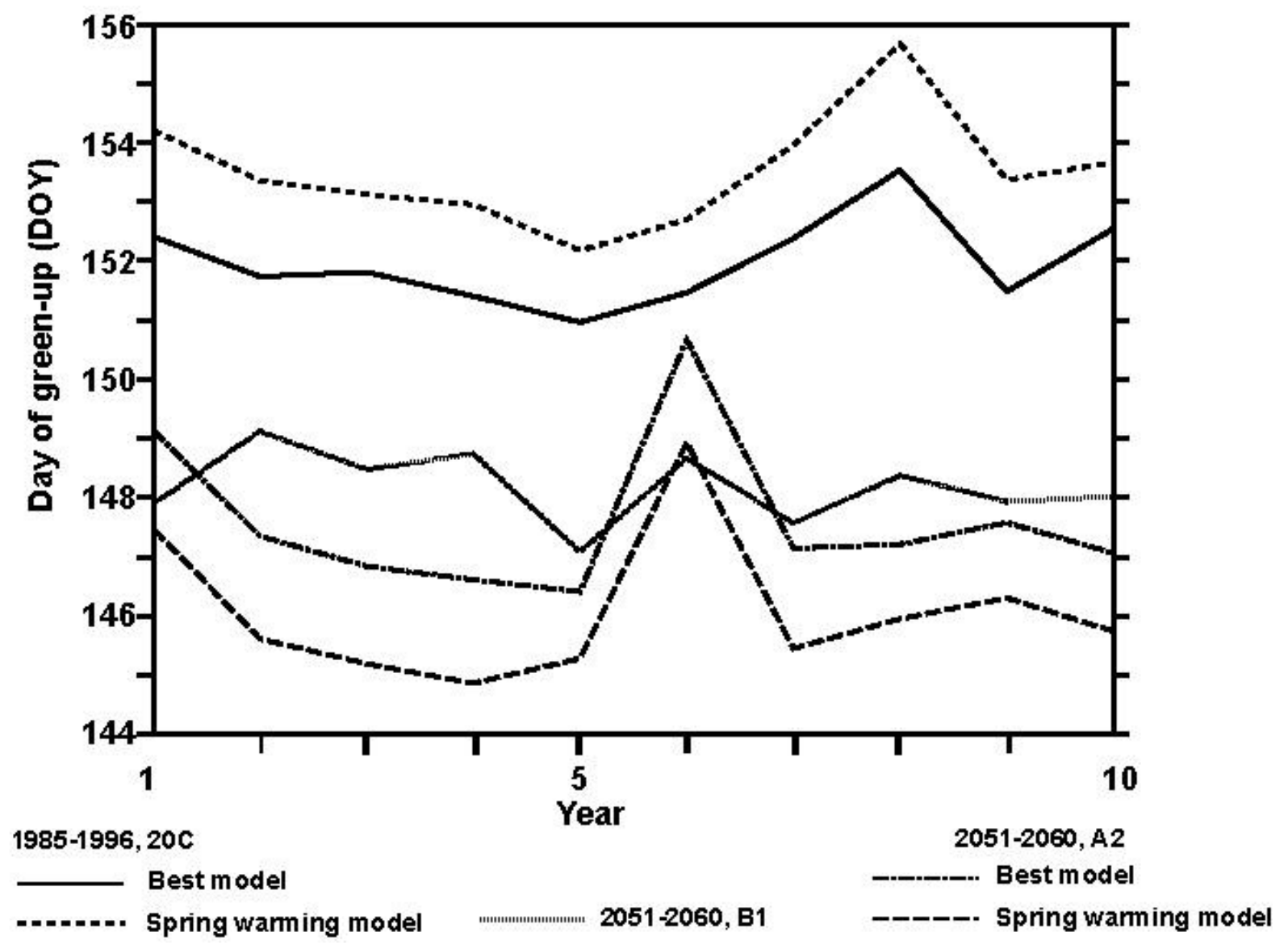

Figure 8 Time of green-up according to the best models determined (solid black line) and from the spring warming models (short dashed black line) using the temperature data from the $20^{\text {th }}$ century control experiment for the 10 years $1986-1995$, from the B1 climate change simulation for 2051-2060 (solid grey line) and according to the best models determined (dash-dot black line) and the spring warming models (long dashed black line) for the A2 climate change simulation for 2051-2060, respectively. For the $20^{\text {th }}$ century control simulation the spring warming models imply a later green-up than the models including chilling demonstrating the effectiveness of chilling reducing the warming required for green-up. For the A2 scenario, however, the spring warming models simulate earlier greenup suggesting that chilling requirements are not fulfilled any more leading to significantly larger warming requirements in the models requiring chilling. 


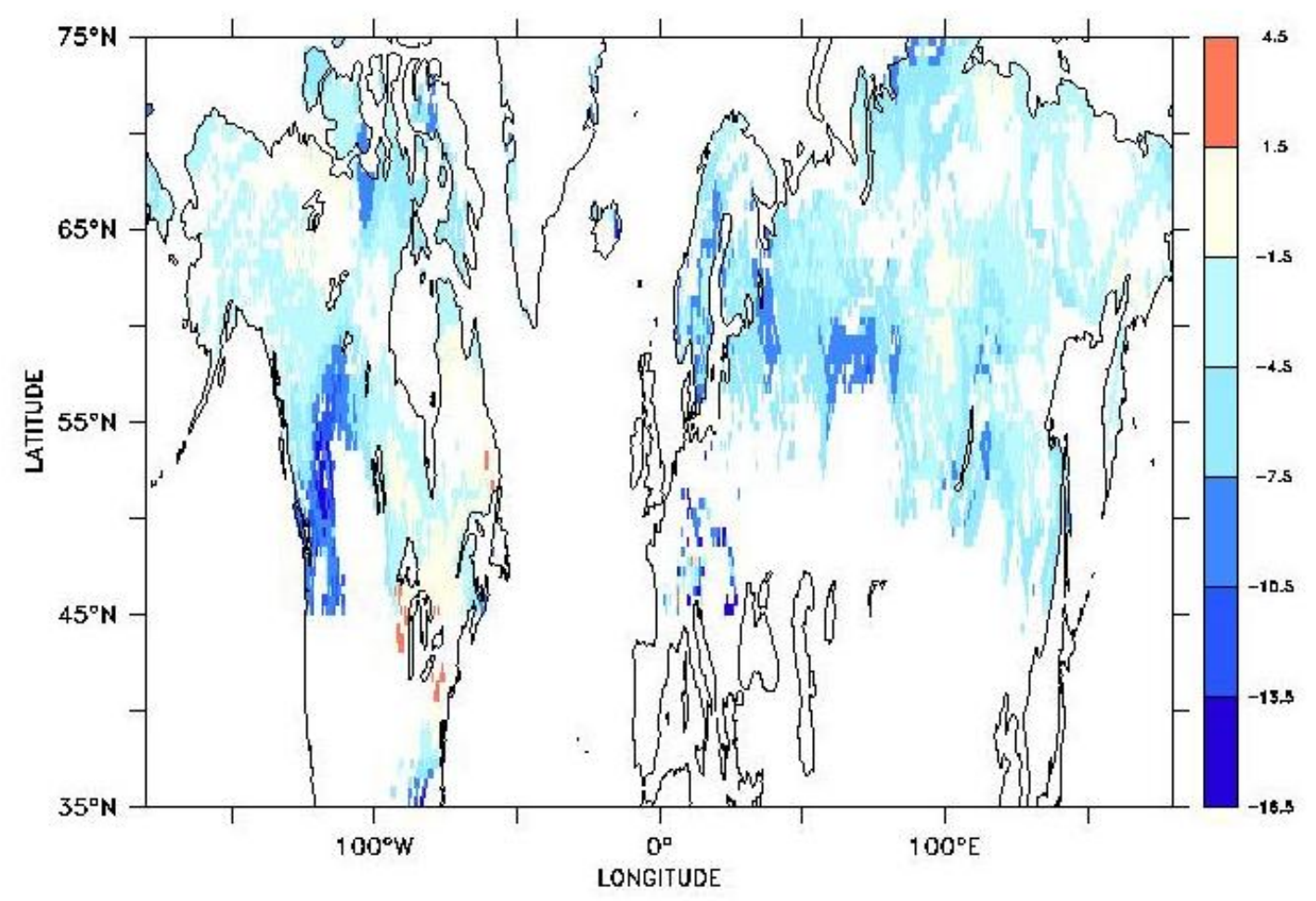

Figure 9 Change in the mean time of green-up (negative means to earlier times) from 19861995 to $2051-2060$ as predicted from the simulated $20^{\text {th }}$ century and the A2 scenario temperatures. 
1 Tables

2

3 Table 1 Number of pixels in the landcover classes and

4 regions in the UMd land cover data and the number of pixels in

5 the Biomes we consider after the screening detailed in Section

62.3 was applied.

\begin{tabular}{|c|c|c|c|c|c|}
\hline \multirow[b]{2}{*}{ Class } & $\begin{array}{l}\text { Numbe } \\
\text { and are }\end{array}$ & f pixels & In landc & ver class & $\begin{array}{l}\text { Number of pixels } \\
\text { in Biome }\end{array}$ \\
\hline & $\overline{\mathrm{NH}}$ & $>30^{\circ} \mathrm{N}$ & $>45^{\circ} \mathrm{N}$ & $>50^{\circ} \mathrm{N}$ & \\
\hline $1 \mathrm{ENF}$ & 1730 & 1714 & 1646 & 1396 & 1646 \\
\hline $3 \mathrm{DNF}$ & 245 & 245 & 245 & 245 & 237 \\
\hline $4 \mathrm{DBF}$ & 233 & 169 & 17 & 0 & 169 \\
\hline $5 \mathrm{MixF}$ & 2268 & 2206 & 1904 & 1500 & 1904 \\
\hline $6 \mathrm{Wdld}$ & 5353 & 4202 & 3491 & 3132 & 3491 \\
\hline 9 OpSh & 7684 & 6838 & 4490 & 3994 & 3994 \\
\hline
\end{tabular}

7 
Table 2 Notation and formulation of the major types of phenology models (Spring Warming,

2 Sequential, Parallel, and Alternating models) tested in this paper following notation from

3 (Chuine et al., 1998; Hanninen, 1990; Kramer, 1996; Murray et al., 1989). There are some slight variations in the literature.

\section{Symb.}

\section{Units Notes and Definitions}

\section{Parameters}

$\mathrm{t}_{\mathrm{C} 0} \quad$ Start date for counting chilling rate

$t_{\mathrm{F} 0} \quad$ Start date for counting forcing rate

$\mathrm{C}^{*} \quad$ Critical value of the state of chilling

If $\mathrm{S}_{\mathrm{c}}(\mathrm{t})>\mathrm{C}^{*}$, then the chilling requirement is fulfilled.

Transition from rest to quiescence.

$\mathrm{F}^{*} \quad$ critical value of the state of forcing $\quad{ }^{\circ} \mathrm{C} \quad$ If $\mathrm{S}_{\mathrm{f}}(\mathrm{t})>\mathrm{F}^{*}$, then budburst occurs

$\mathrm{T}_{\mathrm{c}} \quad$ temperature threshold for chilling $\quad{ }^{\circ} \mathrm{C}$

$\mathrm{T}_{\mathrm{f}} \quad$ temperature threshold for forcing $\quad{ }^{\circ} \mathrm{C}$

\section{Variables}

$\mathrm{t} \quad$ Time day

$\mathrm{T} \quad$ Mean daily temperature $\quad{ }^{\circ} \mathrm{C}$

$\mathrm{T}_{\mathrm{x}} \quad$ Mean annual temperature $(\mathrm{x}=\mathrm{a})$ or $\quad{ }^{\circ} \mathrm{K}$

mean Oct.-Dec. temperature $(\mathrm{x}=\mathrm{w})$

$t_{b b} \quad$ Day of year of bud-burst

$\mathrm{t}_{\mathrm{C} *} \quad$ Day of year when the chilling

requirement is first fulfilled.

$t_{F^{*}} \quad$ Day of year when the forcing

requirement is first fulfilled.

$\mathrm{R}_{\mathrm{c}}(\mathrm{t}) \quad$ Chilling rate function

$$
R_{c}(t)=\left\{\begin{array}{ll}
0 & T>T_{c} \\
1 & T \leq T_{c}
\end{array} \quad t \geq t_{C 0}\right.
$$

$\mathrm{R}_{\mathrm{f}}(\mathrm{t}) \quad$ Forcing rate function

$$
{ }^{\circ} \mathrm{C} \text { day }^{-1} \quad R_{f}(t)=\left\{\begin{array}{cc}
T-T_{f} & T \geq T_{f} \\
0 & T<T_{f}
\end{array} \quad t \geq t_{F 0}\right.
$$


State of chilling, number of chilling
days (NCD) day $\sum_{s=t_{C 0}}^{t} R_{c}(s)$

$\mathrm{S}_{\mathrm{f}}(\mathrm{t})$

State of forcing, growing degree days

(GDD)

${ }^{\circ} \mathrm{C} \quad \sum_{s=t_{F 0}}^{t} R_{f}(s)$

\section{Models}

$\underline{\text { Spring Warming Model }}$

$$
F_{0}(t)=a
$$

Alternating Model

Original form (Murray et al., 1989)

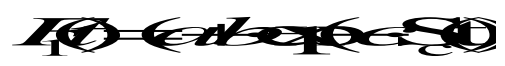

Variations of the Alternating Model including mean temperature $(\mathrm{x}=\mathrm{a}, \mathrm{w})$

Two exponentials

Parameters linearly temperature

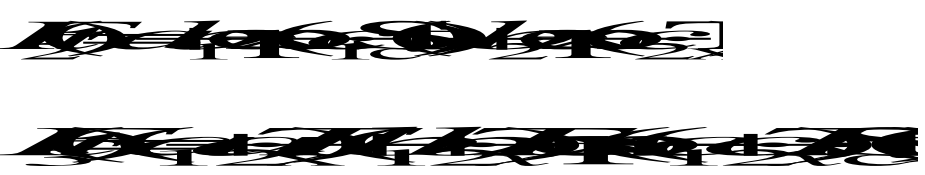

dependent

$$
\begin{aligned}
F_{4}(t) & =\left(a_{1}+a_{2} \cdot T_{x}\right)+ \\
& +\left(b_{1}+b_{2} \cdot T_{x}\right) \cdot \exp \left(-\left(c_{1}+c_{2} \cdot T_{x}\right) \cdot \mathrm{S}_{\mathrm{c}}(\mathrm{t})-d_{1} \cdot T_{x}\right) \\
F_{5}(t)= & a+\left(b_{1}+b_{2} \cdot T_{x}\right) \cdot \exp \left(-\left(c_{1}+c_{2} \cdot T_{x}\right) \cdot \mathrm{S}_{\mathrm{c}}(\mathrm{t})\right)+ \\
& +\left(d_{1}+d_{2} \cdot T_{x}\right) \cdot \exp \left(-\left(e_{1}+e_{2} \cdot T_{x}\right) \cdot \mathrm{S}_{\mathrm{c}}(\mathrm{t})\right)
\end{aligned}
$$


2 Table 3 Number of grid points in land cover classes 1, 3-6, and 9 for

3 which methods a) - d) detect green-up in 1984 as well as the number of

4 points which are snow free and snow covered according to the snow cover

5 data (Armstrong and Brodzik, 2002) at the time of the detected green-up.

6 Also given the mean number of grid points per biome, i.e. the points

7 remaining after the screening detailed in section 2.3 for which green-up was

8 detected, and the mean number of points 1984-1995, which were snow free

9 at the time green-up was detected.

\begin{tabular}{lllll}
\hline Land cover & & \multicolumn{2}{l}{ Mean number of points in } & \multicolumn{2}{l}{ Mean number of points in } \\
class/Biome & & \multicolumn{2}{l}{ land cover class 1984-1995 } & biome 1984-1995 \\
\cline { 1 - 1 } & leaf out & Snow free at & leaf out & Snow free at \\
& detected & leaf out & detected & leaf out \\
\hline
\end{tabular}

Method a

\begin{tabular}{lcccc}
\hline ENF & 1682 & 1301 & 1598 & 1219 \\
DNF & 245 & 143 & 237 & 141 \\
DBF & 229 & 228 & 169 & 168 \\
MixF & 2247 & 1851 & 1865 & 1472 \\
Wdld & 5241 & 4161 & 3416 & 2362 \\
OpSh & 5498 & 3610 & 2447 & 847 \\
\cline { 1 - 3 } Method b & 1689 & 324 & 1601 & 253 \\
\cline { 4 - 5 } ENF & 245 & 9 & 237 & 9 \\
DNF & 215 & 182 & 169 & 139 \\
DBF & 2241 & 631 & 1865 & 331 \\
MixF & & & & \\
\hline
\end{tabular}




\begin{tabular}{|c|c|c|c|c|}
\hline Wdld & 5150 & 2013 & 3417 & 451 \\
\hline OpSh & 6024 & 2560 & 2547 & 119 \\
\hline \multicolumn{5}{|l|}{ Method c } \\
\hline ENF & 1697 & 1490 & 1604 & 1402 \\
\hline DNF & 245 & 206 & 237 & 200 \\
\hline DBF & 230 & 225 & 169 & 166 \\
\hline MixF & 2251 & 2002 & 1865 & 1626 \\
\hline Wdld & 5285 & 4553 & 3418 & 2756 \\
\hline OpSh & 6169 & 4907 & 2509 & 1556 \\
\hline \multicolumn{5}{|l|}{ Method d } \\
\hline ENF & 1690 & 187 & 1602 & 121 \\
\hline DNF & 245 & 0 & 237 & 0 \\
\hline DBF & 216 & 133 & 169 & 88 \\
\hline MixF & 2242 & 273 & 1865 & 61 \\
\hline Wdld & 5170 & 1610 & 3417 & 131 \\
\hline OpSh & 6149 & 2317 & 2547 & 60 \\
\hline
\end{tabular}

2 
2 Table 4 Mean day of year of green-up 1984-1995 for the methods a) - d) per biome for the cases

3 (A) when all pixels are considered, and (B) when only those cells are considered which were snow free

4 at the time of the detected green-up.

Mean day of leaf out 1983-1995 mean

A All pixels

B Only Snow free pixels at leaf out

\begin{tabular}{|c|c|c|c|c|c|c|c|c|c|c|c|c|}
\hline \multirow[b]{2}{*}{ Method } & \multicolumn{6}{|c|}{ Biome } & \multicolumn{6}{|c|}{ Biome } \\
\hline & ENF & DNF & DBF & MixF & Wdld & OpSh & ENF & DNF & DBF & MixF & Wdld & OpSh \\
\hline a) & 145.6 & 147.7 & 112.7 & 137.6 & 144.7 & 174.7 & 145.7 & 143.1 & 112.7 & 136.2 & 141.0 & 168.0 \\
\hline b) & 126.4 & 136.5 & 89.6 & 122.2 & 129.8 & 167.7 & 108.5 & 112.7 & 93.1 & 106.5 & 105.9 & 161.9 \\
\hline c) & 154.0 & 153.3 & 113.3 & 144.4 & 150.9 & 180.5 & 153.6 & 152.9 & 113.8 & 144.1 & 149.6 & 180.4 \\
\hline d) & 126.3 & 142.4 & 75.0 & 122.3 & 132.5 & 170.4 & 121.0 & 131.5 & 71.2 & 114.1 & 122.2 & 178.6 \\
\hline
\end{tabular}

5

6

7 
Table 5 Number of successful fits, average and

2 standard deviation of the mean absolute GDD error mean

3 1984-1995 of the fit to the NCD-GDD relationship with

4 functions $\mathrm{F}_{0}-\mathrm{F}_{3}$ to the leaf out dates from method a)

5 considering snow free pixels at leaf out only. For $F_{2} \& F_{3}$

6 the mean annual temperature, $\mathrm{T}_{\mathrm{a}}$, was used in the fits.

GDD mean absolute error 1984-1995 mean

\begin{tabular}{|c|c|c|c|c|c|c|}
\hline \multirow[t]{2}{*}{ Function } & \multicolumn{6}{|c|}{ Biome } \\
\hline & ENF & DNF & DBF & MixF & Wdld & OpSh \\
\hline \multicolumn{7}{|l|}{$\overline{\mathrm{F}_{0}}$} \\
\hline No. fits & 12 & 12 & 12 & 12 & 12 & 12 \\
\hline Ave & 126.22 & 33.52 & 192.29 & 78.23 & 96.15 & 71.86 \\
\hline Std & 15.71 & 11.48 & 34.09 & 7.45 & 8.98 & 8.34 \\
\hline \multicolumn{7}{|l|}{$\overline{\mathrm{F}_{1}}$} \\
\hline No. fits & 12 & 9 & 12 & 12 & 12 & 12 \\
\hline Ave & 94.02 & 28.47 & 76.08 & 67.95 & 77.26 & 56.44 \\
\hline Std & 15.84 & 10.62 & 10.28 & 7.90 & 8.80 & 7.09 \\
\hline \multicolumn{7}{|l|}{$\mathrm{F}_{2}\left(\mathrm{~T}_{\mathrm{a}}\right)$} \\
\hline No. fits & 8 & 5 & 6 & 9 & 6 & 9 \\
\hline Ave & 90.93 & 27.93 & 67.76 & 65.34 & 73.45 & 50.97 \\
\hline Std & 16.37 & 8.13 & 8.73 & 8.77 & 7.60 & 4.61 \\
\hline \multicolumn{7}{|l|}{$\overline{F_{2}}\left(T_{w}\right)$} \\
\hline No. fits & 7 & 6 & 6 & 9 & 9 & 9 \\
\hline Ave & 94.95 & 29.01 & 70.42 & 64.59 & 74.42 & 54.18 \\
\hline Std & 14.62 & 6.55 & 7.75 & 8.47 & 6.91 & 8.62 \\
\hline
\end{tabular}

$\mathrm{F}_{3}\left(\mathrm{~T}_{\mathrm{a}}\right)$ 


\begin{tabular}{|c|c|c|c|c|c|c|}
\hline No. fits & 12 & 3 & 11 & 7 & 7 & 12 \\
\hline Ave & 90.75 & 30.59 & 67.52 & 65.48 & 72.81 & 52.35 \\
\hline Std & 14.58 & 7.29 & 7.68 & 8.33 & 10.94 & 6.59 \\
\hline \multicolumn{7}{|l|}{$\overline{\mathrm{F}_{3}\left(\mathrm{~T}_{\mathrm{w}}\right)}$} \\
\hline No. fits & 11 & 7 & 12 & 9 & 11 & 11 \\
\hline Ave & 85.59 & 25.49 & 68.53 & 65.64 & 75.03 & 52.91 \\
\hline Std & 10.15 & 9.74 & 6.74 & 8.22 & 8.97 & 7.81 \\
\hline \multicolumn{7}{|l|}{$\mathrm{F}_{5}\left(\mathrm{~T}_{\mathrm{a}}\right)$} \\
\hline No. fits & 10 & 6 & 4 & 6 & 4 & 4 \\
\hline Ave & 91.85 & 27.13 & 59.44 & 60.71 & 75.14 & 52.64 \\
\hline Std & 13.20 & 10.38 & 6.31 & 6.39 & 2.46 & 4.10 \\
\hline \multicolumn{7}{|l|}{$\overline{\mathrm{F}_{5}\left(\mathrm{~T}_{\mathrm{w}}\right)}$} \\
\hline No. fits & 5 & 6 & 7 & 8 & 4 & 6 \\
\hline Ave & 84.26 & 22.67 & 61.69 & 60.21 & 72.27 & 49.99 \\
\hline Std & 12.34 & 9.12 & 5.87 & 4.17 & 2.73 & 4.37 \\
\hline
\end{tabular}


Table 612 year mean average error in green up date for methods a) and c) and functions $\mathrm{F}_{0}$,

$2 \quad F_{1}$ and $F_{3}$. The upper eight rows show the mean errors from fitting each function each year for

3 the year they were fitted on. The lower eight rows show the mean absolute prediction errors

4 from Leave One Out Cross Validation (LOO CV, i.e. fitting the functions on 11 years and

5 predicting the $\left.12^{\text {th }}\right)$. The large errors from some combinations are due to $1-3$ outliers where the

6 minimization algorithm could not find a good fit.

12 year mean average absolute error in green up

Biome

Model ENF DNF DBF MixF Wdld OpSh

Mean error in the year used for fitting

Method a)

$\begin{array}{lcccccc}\mathrm{F}_{0} & 13.37 & 4.75 & 16.96 & 8.90 & 10.97 & 10.18 \\ \mathrm{~F}_{1} & 9.84 & 33.74 & 6.82 & 7.62 & 8.71 & 7.77 \\ \mathrm{~F}_{3}, \mathrm{~T}_{\mathrm{a}} & 18.20 & 50.00 & 6.13 & 11.74 & 8.31 & 36.04 \\ \mathrm{~F}_{3}, \mathrm{~T}_{\mathrm{w}} & 13.83 & 54.39 & 6.58 & 12.06 & 8.53 & 8.28\end{array}$

Method c)

$\begin{array}{lllllll}\mathrm{F}_{0} & 11.60 & 3.01 & 16.80 & 8.60 & 9.08 & 4.33 \\ \mathrm{~F}_{1} & 9.64 & 2.66 & 7.11 & 7.91 & 7.72 & 3.80 \\ \mathrm{~F}_{3}, \mathrm{~T}_{\mathrm{a}} & 9.36 & 28.54 & 6.02 & 7.88 & 7.47 & 5.50 \\ \mathrm{~F}_{3}, \mathrm{~T}_{\mathrm{w}} & 27.15 & 23.17 & 6.34 & 12.29 & 6.93 & 4.55\end{array}$

Mean prediction error from $\mathrm{LOO} \mathrm{CV}$

Method a)

$\begin{array}{lllllll}\mathrm{F}_{0} & 13.50 & 5.47 & 19.00 & 8.99 & 11.00 & 10.51 \\ \mathrm{~F}_{1} & 10.09 & 5.36 & 10.01 & 7.77 & 8.88 & 8.06\end{array}$




$\begin{array}{lllllll}\mathrm{F}_{3}, \mathrm{~T}_{\mathrm{a}} & 9.94 & 21.88 & 9.61 & \text { N/A } & 8.39 & 7.84 \\ \mathrm{~F}_{3}, \mathrm{~T}_{\mathrm{w}} & 9.82 & 118.74 & 10.14 & 7.74 & 9.17 & 44.33\end{array}$

Method c)

$\begin{array}{lllllll}\mathrm{F}_{0} & 12.25 & 3.38 & 18.37 & 8.71 & 9.12 & 4.30 \\ \mathrm{~F}_{1} & 10.53 & 3.38 & 10.20 & 8.14 & 7.99 & 3.82 \\ \mathrm{~F}_{3}, \mathrm{~T}_{\mathrm{a}} & 10.55 & 6.62 & 10.22 & \mathrm{~N} / \mathrm{A} & 7.67 & 3.71 \\ \mathrm{~F}_{3}, \mathrm{~T}_{\mathrm{w}} & 10.31 & 44.15 & 21.22 & 8.10 & 7.83 & 3.74\end{array}$


Table 7 Parameters for the selected models from the 12 LOO CV runs for every other year 1984-1995 and the parameters resulting when the data of all twelve years are used. Years indicate which year was left out from the model calibration. Parameter values are quite similar for all model calibrations. Typically the parameter values resulting from the calibration using all twelve years of data are very close to the values from the LOO CV calibrations.

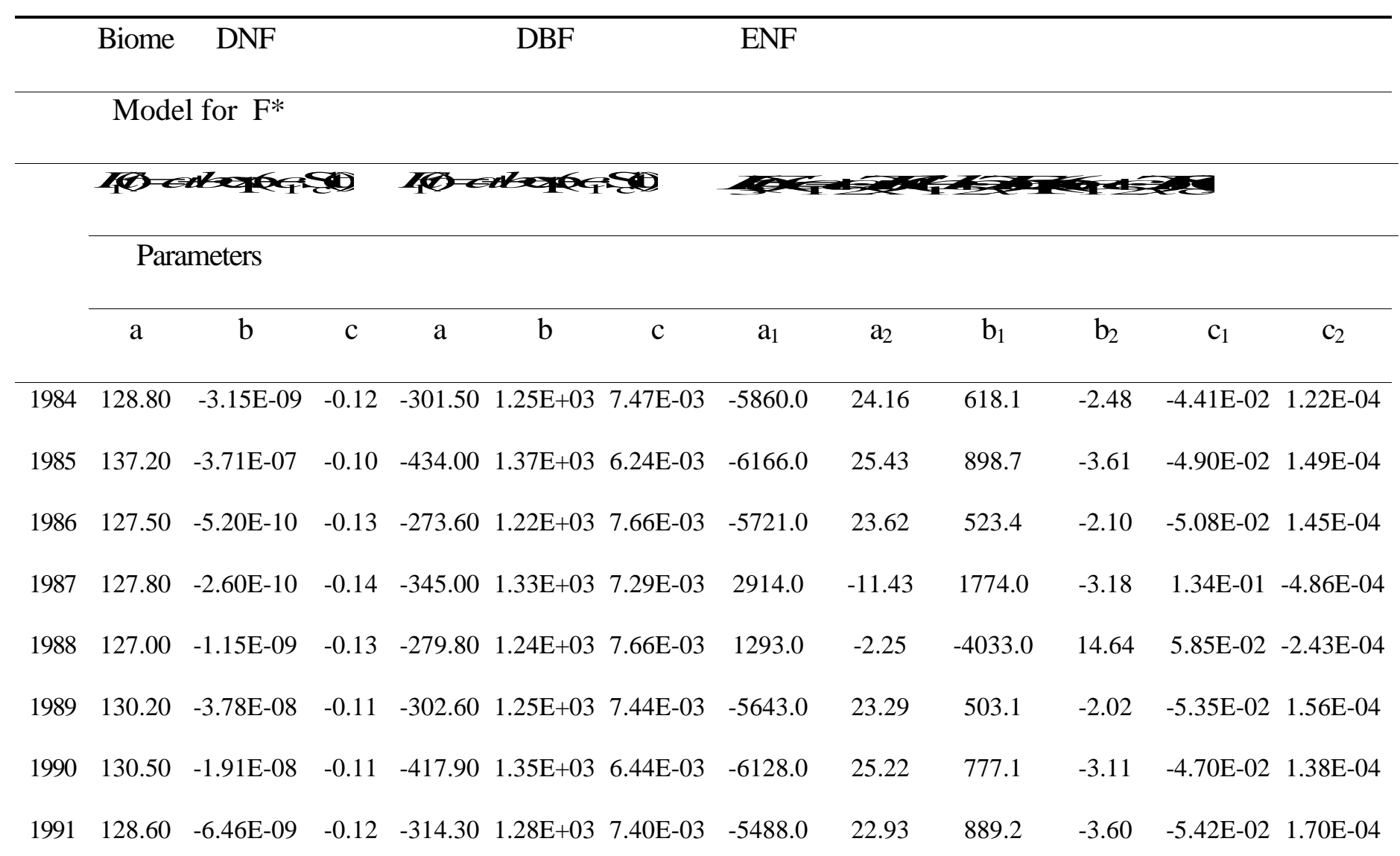

Page 53 


\begin{tabular}{lrrrrrrrrrrrrrr}
1992 & 128.00 & $-1.71 \mathrm{E}-08$ & -0.11 & -396.20 & $1.34 \mathrm{E}+03$ & $6.60 \mathrm{E}-03$ & -6005.0 & 24.92 & 1042.0 & -4.20 & $-5.11 \mathrm{E}-02$ & $1.59 \mathrm{E}-04$ \\
1993 & 123.90 & $-3.70 \mathrm{E}-09$ & -0.12 & -479.60 & $1.42 \mathrm{E}+03$ & $6.04 \mathrm{E}-03$ & 2771.0 & -10.82 & 2610.0 & -6.22 & $1.42 \mathrm{E}-01$ & $-5.14 \mathrm{E}-04$ \\
1994 & 126.00 & $-3.38 \mathrm{E}-09$ & -0.12 & -677.10 & $1.63 \mathrm{E}+03$ & $5.02 \mathrm{E}-03$ & -1871.0 & 9.25 & -1921.0 & 7.00 & $1.05 \mathrm{E}-01$ & $-4.30 \mathrm{E}-04$ \\
1995 & 124.60 & $-4.59 \mathrm{E}-12$ & -0.15 & -465.10 & $1.41 \mathrm{E}+03$ & $6.09 \mathrm{E}-03$ & -6159.0 & 25.12 & 332.4 & -1.32 & $-4.22 \mathrm{E}-02$ & $1.02 \mathrm{E}-04$ \\
\hline Mean & 128.30 & $-3.86 \mathrm{E}-08$ & -0.12 & -390.60 & $1.34 \mathrm{E}+03$ & $6.78 \mathrm{E}-03$ & -3505.0 & 14.95 & 334.5 & -0.85 & $3.93 \mathrm{E}-03$ & $-4.43 \mathrm{E}-05$ \\
Stddev & 3.42 & $1.05 \mathrm{E}-07$ & 0.01 & 115.90 & $1.14 \mathrm{E}+02$ & $8.35 \mathrm{E}-04$ & 3723.0 & 14.77 & 1729.0 & 5.82 & $8.07 \mathrm{E}-02$ & $2.84 \mathrm{E}-04$ \\
\hline
\end{tabular}

Parameters from fit using all 12 years

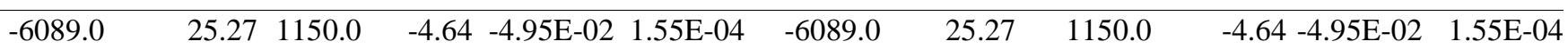


Table 8 continued

Biome

Wdld

$\mathrm{OpSH}$

Model for $\mathrm{F}^{*}$

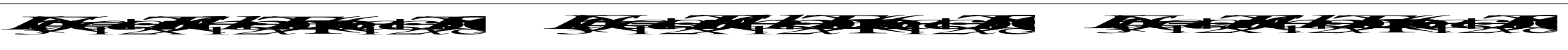

$\begin{array}{llllllllllllllllllllll}\mathrm{a}_{1} & \mathrm{a}_{2} & \mathrm{~b}_{1} & \mathrm{~b}_{2} & \mathrm{c}_{1} & \mathrm{c}_{2} & \mathrm{a}_{1} & \mathrm{a}_{2} & \mathrm{~b}_{1} & \mathrm{~b}_{2} & \mathrm{c}_{1} & \mathrm{c}_{2} & \mathrm{a}_{1} & \mathrm{a}_{2} & \mathrm{~b}_{1} & \mathrm{~b}_{2} & \mathrm{c}_{1} & \mathrm{c}_{2}\end{array}$

$1984 \quad$\begin{tabular}{llllllllllllllllll}
\hline-774.6 & 3.31 & $3.47 \mathrm{e}+03$ & -10.15 & $2.10 \mathrm{e}-02$ & $-3.36 \mathrm{e}-05$ & -2528.0 & 9.58 & $1.50 \mathrm{e}+04$ & -51.91 & $7.24 \mathrm{e}-02$ & $-2.22 \mathrm{e}-04$ & -5648.0 & 23.14 & 1510.00 & -6.09 & $-1.56 \mathrm{e}-02$ & $3.57 \mathrm{e}-05$
\end{tabular}

$\begin{array}{lllllllllllllllllllllll}1985 & -434.5 & 2.16 & 9.60 \mathrm{e}+03 & -32.40 & 8.18 \mathrm{e}-02 & -2.49 \mathrm{e}-04 & -2739.0 & 10.35 & 1.64 \mathrm{e}+04 & -56.59 & 6.64 \mathrm{e}-02 & -1.99 \mathrm{e}-04 & -8408.0 & 34.25 & 3833.00 & -15.45 & -1.27 \mathrm{e}-02 & 3.42 \mathrm{e}-05\end{array}$

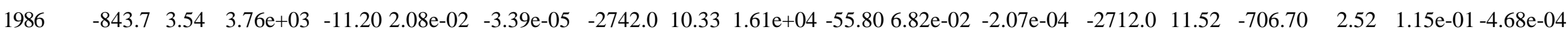

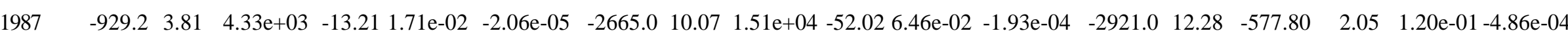

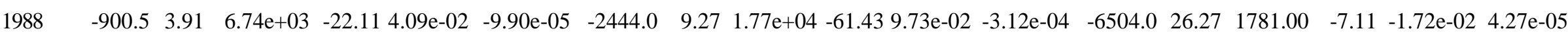

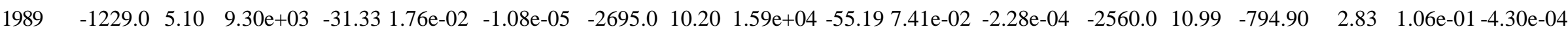

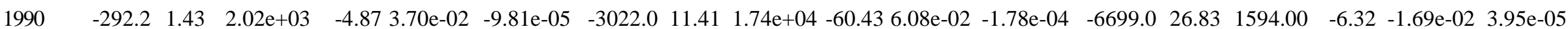

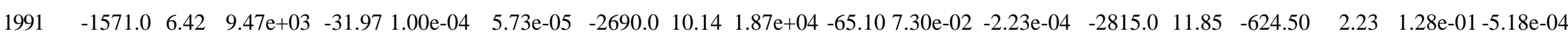

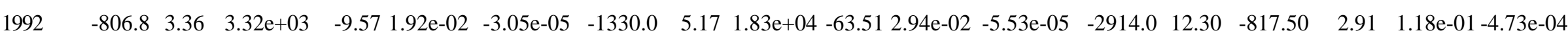

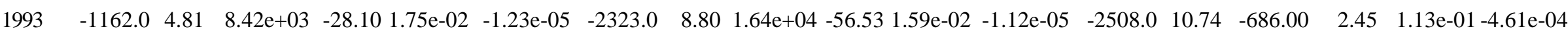

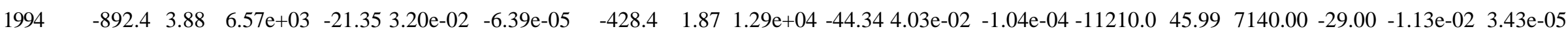

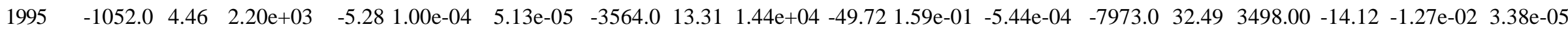
$\begin{array}{lllllllllllllllllllllll}\text { Mean } & -907.3 & 3.85 & 5.77 \mathrm{e}+03 & -18.46 & 2.54 \mathrm{e}-02 & -4.52 \mathrm{e}-05 & -2431.0 & 9.21 & 1.62 \mathrm{e}+04 & -56.05 & 6.84 \mathrm{e}-02 & -2.06 \mathrm{e}-04 & -5239.0 & 21.55 & 1262.00 & -5.26 & 5.11 \mathrm{e}-02 & -2.18 \mathrm{e}-04\end{array}$

Page 55 
Parameters from fit using all 12 years

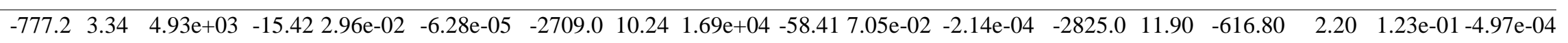


Table 8 Definition and error characteristics of the selected models for green-up for the biomes considered here. The models are calibrated using the varpro algorithm and GDD and NCD data from the years $1984-1995$ with $t_{\mathrm{C} 0}$ and $t_{\mathrm{F} 0}$ set to the first of November and the first of January, respectively, and the threshold temperatures for chilling and forcing set to zero, $T_{c}=$ $T_{f}=0$. Error data are based on 12 LOO CV runs for the years 1984-1995.

\begin{tabular}{|c|c|c|c|c|}
\hline \multirow[t]{4}{*}{ Biome } & \multirow{4}{*}{ Model for $\mathrm{F}^{*}$} & \multirow{3}{*}{\multicolumn{3}{|c|}{$\begin{array}{l}\text { Green-up } \\
\text { prediction } \\
\text { error (days) }\end{array}$}} \\
\hline & & & & \\
\hline & & & & \\
\hline & & Mean & Std. dev. & Range \\
\hline ENF & $\begin{aligned} F_{3}(t) & =\left(-6089+26.3 \cdot T_{w}\right)+\left(1150-4.64 \cdot T_{w}\right) \\
& \cdot \exp \left(-\left(0.049-0.000155 \cdot T_{w}\right) \cdot \mathrm{S}_{\mathrm{c}}(\mathrm{t})\right)\end{aligned}$ & $\overline{9.82}$ & 1.41 & $7.3-13.1$ \\
\hline $\mathrm{DNF}$ & $F_{l}(t)=127.8-2.610^{-9} \exp \left(\left(-0.123 \mathrm{~S}_{\mathrm{c}}(\mathrm{t})\right)\right.$ & 5.36 & 1.46 & $2.7-7.2$ \\
\hline & $F_{0}(t)=115.2$ & 5.47 & 1.40 & $2.7-7.6$ \\
\hline DBF & $F_{l}(t)=-381.7+1333 \exp \left(\left(-0.00674 \mathrm{~S}_{\mathrm{c}}(\mathrm{t})\right)\right.$ & 9.61 & 3.81 & $6.0-20.4$ \\
\hline MixF & $\begin{aligned} F_{3}(t)= & \left(-777.2+3.344 \cdot T_{w}\right)+\left(492.8-15.42 \cdot T_{w}\right) \\
& \cdot \exp \left(-\left(0.02956+0.000063 \cdot T_{w}\right) \cdot \mathrm{S}_{\mathrm{c}}(\mathrm{t})\right)\end{aligned}$ & 7.74 & 1.13 & $6.8-9.5$ \\
\hline Wdld & $\begin{aligned} F_{3}(t)= & \left(-2709+10.24 \cdot T_{a}\right)+\left(1686-58041 \cdot T_{a}\right) \\
& \cdot \exp \left(\left(0.0705-0.000214 \cdot T_{a}\right) \cdot \mathrm{S}_{\mathrm{c}}(\mathrm{t})\right)\end{aligned}$ & 8.39 & 0.64 & $7.3-9.4$ \\
\hline OpSh & $\begin{aligned} F_{3}(t) & =\left(-2825+11.9 \cdot T_{\mathrm{a}}\right)+\left(-616.8+2.2 \cdot T_{a}\right) \\
& \cdot \exp \left(\left(0.1226-0.000497 \cdot T_{a}\right) \cdot \mathrm{S}_{\mathrm{c}}(\mathrm{t})\right)\end{aligned}$ & 7.84 & 1.19 & $6.9-8.6$ \\
\hline
\end{tabular}

